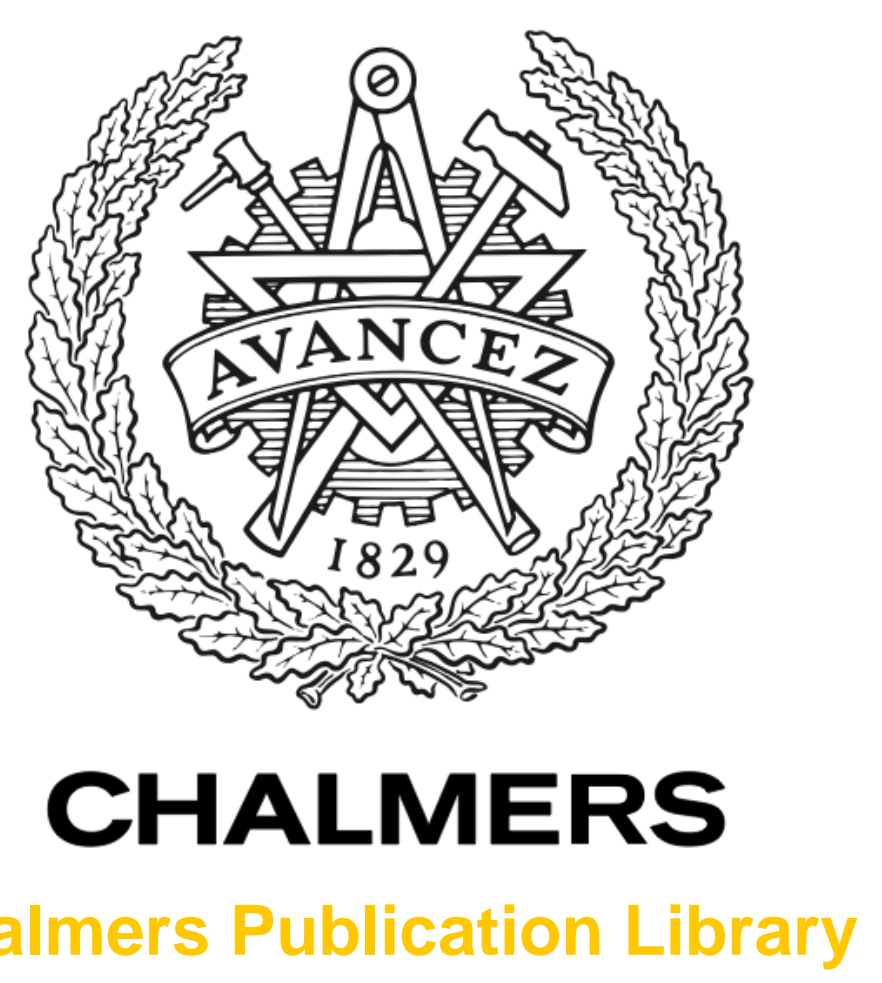

Chalmers Publication Library

Critical Aspects of Alloying of Sintered Steels with Manganese

This document has been downloaded from Chalmers Publication Library (CPL). It is the author's version of a work that was accepted for publication in:

Metallurgical and Materials Transactions A - Physical Metallurgy and Materials Science (ISSN: 1073-5623)

Citation for the published paper:

Hryha, E. ; Dudrova, E. ; Nyborg, L. (2010) "Critical Aspects of Alloying of Sintered Steels with Manganese". Metallurgical and Materials Transactions A - Physical Metallurgy and Materials Science, vol. 41A(11), pp. 2880-2897.

http://dx.doi.org/10.1007/s11661-010-0357-5

Downloaded from: http://publications.lib.chalmers.se/publication/128722

Notice: Changes introduced as a result of publishing processes such as copy-editing and formatting may not be reflected in this document. For a definitive version of this work, please refer to the published source. Please note that access to the published version might require a subscription.

Chalmers Publication Library (CPL) offers the possibility of retrieving research publications produced at Chalmers University of Technology. It covers all types of publications: articles, dissertations, licentiate theses, masters theses, conference papers, reports etc. Since 2006 it is the official tool for Chalmers official publication statistics. To ensure that Chalmers research results are disseminated as widely as possible, an Open Access Policy has been adopted.

The CPL service is administrated and maintained by Chalmers Library. 


\title{
Critical Aspects of Alloying of Sintered Steels with Manganese
}

\author{
EDUARD HRYHA, EVA DUDROVA, and LARS NYBORG
}

\begin{abstract}
This study examines the sintering behavior and properties of $\mathrm{Fe}-0.8 \mathrm{Mn}-0.5 \mathrm{C}$ manganese powder metallurgy steels. The study focuses on the influence of mode of alloying - admixing using either high-purity electrolytic manganese or medium carbon ferromanganese as well as the fully prealloying of water-atomized powder. Three main aspects were studied during the whole sintering process - microstructure development, interparticle necks evolution, and changes in the behavior of manganese carrier particles during both heating and sintering stages. The prealloyed powder shows considerable improvement in carbon homogenization and interparticle neck development in comparison with admixed materials. The first indication of pearlite for the fully prealloyed material was registered at $\sim 1013 \mathrm{~K}\left(740{ }^{\circ} \mathrm{C}\right)$ in comparison with $\sim 1098 \mathrm{~K}$ $\left(825^{\circ} \mathrm{C}\right)$ in the case of the admixed systems. The negative effect of the oxidized residuals of manganese carrier particles and high microstructure inhomogeneity, which is a characteristic feature of admixed systems, is reflected in the lower values of the mechanical properties. The worst results in this respect were obtained for the system admixed with electrolytic manganese because of more intensive manganese sublimation and resulting oxidation at lower temperatures. According to the results of X-ray photoelectron spectroscopy and high-resolution scanning electron microscopy and energy dispersive X-ray analyses, the observed high brittleness of admixed materials is connected with intergranular decohesion failure associated with manganese oxide formation on the grain boundaries.
\end{abstract}

DOI: $10.1007 / \mathrm{s} 11661-010-0357-5$

(c) The Minerals, Metals \& Materials Society and ASM International 2010

\section{INTRODUCTION}

POWDER metallurgy (PM) is a technology for the large-scale manufacturing of precision parts for the automotive industry, for example. The profitable PM manufacturing route for structural parts manufacture consists of compaction and sintering stages and gives high productivity with low energy consumption and high material utilization. However, residual porosity is an inalienable feature of the pressed and sintered PM parts. Hence, the resulting mechanical properties (yield and tensile strength, fatigue endurance, etc.) are usually inferior in comparison with the same parts produced by machining of wrought material and precision casting. To tailor the mechanical properties of PM steels, the addition of various alloying elements is required. The choice of alloying element (and its quantity) depends on the properties that have to be improved. Traditionally, PM high-strength steels are alloyed with $\mathrm{Cu}, \mathrm{Ni}$, and Mo, whereas conventional low alloy structural steels contain mostly $\mathrm{Cr}, \mathrm{Mn}$, and $\mathrm{Si}$ along with some addition of carbide formers like $\mathrm{V}$ and Mo. The price of currently employed PM alloying elements like $\mathrm{Mo}$ and $\mathrm{Ni}$ is

EDUARD HRYHA, Assistant Professor, and LARS NYBORG, Professor, are with the Department of Materials and Manufacturing Technology, Chalmers University of Technology, Rännvägen 2A, SE - 41296 Gothenburg, Sweden. Contact e-mail: hryha@chalmers.se EVA DUDROVA, Associate Professor, is with the Institute of Materials Research, Slovak Academy of Science, Watsonova 47, 04353 Košice, Slovakia.

Manuscript submitted March 13, 2010.

Article published online July 9, 2010 dozens of times higher in comparison with that of $\mathrm{Cr}$ or $\mathrm{Mn} .{ }^{[1]}$ This situation creates a strong economical stimulation to introduce cheaper and more efficient alloying elements to improve the competitiveness of PM structural parts.

In the last three decades, the potential in using manganese in PM for the realization of precision structural parts with high static and dynamic properties has been addressed extensively. ${ }^{[2-24]}$ However, the issue periodically has amounted to how to obtain high-quality manganese containing PM steels, or in other words, what type of alloying method is better to use? Different approaches of alloying with manganese have been proposed (e.g., prealloying or admixing), but none of them have been adopted widely in industry.

Powder systems admixed with manganese were proposed first and have been scrutinized for the last 30 years. ${ }^{[5-21]}$ The driving force for possible sintering of such highly oxygen-sensitive powder systems was the so-called "self-cleaning" effect discovered by Šalak. ${ }^{[6-11]}$ The effect is related to the high volatility of manganese that leads to significant manganese sublimation at elevated temperatures. The manganese vapor then is supposed to prevent the specimen from subsequent oxidation. Manganese sublimates at relatively low temperatures, and its partial pressure reaches about $10^{-3} \mathrm{~Pa}$ at $973 \mathrm{~K}\left(700^{\circ} \mathrm{C}\right.$ ) (Figure 1$)$ when thermodynamic conditions also favor its oxidation. The manganese vapor then reacts with the oxygen in the sintering atmosphere according to the following reaction: $2 \mathrm{Mn}_{\text {(gas) }}+\mathrm{O}_{2} \rightarrow 2 \mathrm{MnO}$. If sintering is performed in an atmosphere with low oxygen partial pressure, then 


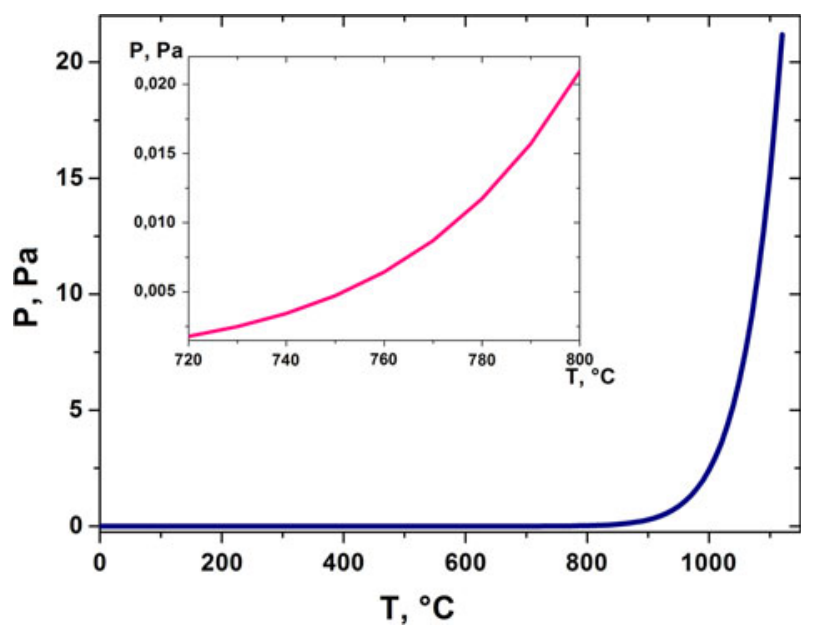

Fig. 1-Equilibrium partial pressure of $\mathrm{Mn}_{\text {gas }}$, showing its substantial increase from $\sim 973 \mathrm{~K}\left(700^{\circ} \mathrm{C}\right)$ - HSC Chemistry 6.1 .

the reaction between $\mathrm{Mn}_{\text {(gas) }}$ and oxygen occurs at greater distances from the surface of the parts. At higher oxygen partial pressure, the oxidation of manganese will be more extensive and include the formation of a greenish $\mathrm{MnO}$ film on the surface of parts. ${ }^{[6-10]}$ Furthermore, high manganese vapor pressure during the heating stage leads to improved homogenization in $\mathrm{Fe}-\mathrm{Mn}$ powder compacts. This homogenization involves manganese vapor being distributed through interconnected pores within the compact. After condensing on free surfaces (e.g., pores), manganese can diffuse into the iron lattice.

According to Cias et al., ${ }^{[16]}$ the first important reaction of manganese vapor is with water vapor, which results in the formation of $\mathrm{H}_{2}$ in the microclimate through the reaction $\mathrm{Mn}_{\text {(gas) }}+\mathrm{H}_{2} \mathrm{O}_{\text {(vapor) }} \rightarrow \mathrm{MnO}+$ $\mathrm{H}_{2 \text { (gas) }}$. The product of this reaction is fine dispersed $\mathrm{MnO}$ that is condensed on free powder surfaces, which hampers the development of interparticle connections. This issue leads to weak interparticles necks and, hence, to lower mechanical properties. To avoid the formation of oxide networks, Mitchel et al. ${ }^{[16,17]}$ proposed a method employing a semiclosed container to create an active "microclimate" around and within the Fe-Mn-C compacts. Another alternative is sintering in a hydrogen atmosphere with low enough dew point dictated by the Ellingham-Richardson diagram. In the hydrogen-rich sintering atmosphere, it is important to maintain both high atmosphere purity and adequate gas flow when oxides are reduced and water vapor forms to minimize potentially oxidizing water vapor in contact with the specimens during sintering ("the specimen's microclimate"). Unfortunately, neither using a hydrogen atmosphere with low enough dew point nor using a semiclosed container with getter material to assure sintering of high-quality products has been approved in industrial practice as suitable for large-scale production. Another characteristic of manganese-admixed systems is intergranular decohesion facets around ferromanganese residues, which leads to brittle behavior for the obtained microstructure. ${ }^{[13,14,19-21]}$
The second way of applying $\mathrm{Mn}$ in sintered steel deals with alloying by using different master alloys in powder form. This technique allowed the successful introduction of a high oxygen affinity element like $\mathrm{Mn}$ in PM industrial production in the late $1970 \mathrm{~s}^{[2-4]}$ The first developed master alloys containing manganesechromium-molybdenum and manganese-vanadiummolybdenum resulted in sintered steel with a wide range of mechanical properties, which depended on alloying content, sintered density, and processing conditions. Thus, it was possible to select optimum material and technology for obtaining the required sintered steel for various applications. Nevertheless, this master-alloy concept also was faced with many issues during application (oxides formation during manufacturing process, high hardness of master-alloy particles that lead to intensive wear of compacting tools, etc). For these reasons, the master-alloy concept disappeared fully from manufacturing and research. However, the more recent development of more diluted master alloys as Fe-Ni-CrMn-Mo-C has been more successful and has shown promising properties for future industrial use. ${ }^{[22-24]}$

The best solution to introduce manganese is by using prealloyed steel powder, which gives a homogeneous sintered microstructure without large pores and contaminated residues from manganese carrier particles. Prealloying also leads to decreasing manganese activity, which means a decreasing overall oxygen affinity of Mn-containing powder. This decrease allows the use of more practicably realistic sintering conditions. The development of water-atomized powder prealloyed with manganese alone or in combination with chromium began in the late 1980s and has continued until now. ${ }^{[25,26]}$ However, conventional annealing of such water-atomized powder faces some difficulties concerning the decrease of oxygen content of the Cr-Mn-alloyed powder to a reasonable level in industrial practice. Highquality chromium-alloyed steel powders currently are successfully industrially produced by means of water atomization. ${ }^{[27,28]} \mathrm{A}$ recent study ${ }^{[29]}$ shows that the quality of the manganese prealloyed powder from the surface composition point of view is comparable with industrial $\mathrm{Cr}$ or $\mathrm{Mo}$ alloyed grades that allow us to expect the appearance of manganese alloyed steel powder on the market in near future. One possible drawback with manganese use in the prealloyed state is the expected lower compressibility of such prealloyed powder because of the strong ferrite solid solution strengthening by manganese. However, recent studies $^{[20,30-32]}$ indicate that a low content of alloying elements like $\mathrm{Mn}$ and $\mathrm{Cr}$ has a limited detrimental effect on the compressibility, provided that proper morphology and fraction composition of prealloyed powder are maintained.

\section{THERMODYNAMIC EVALUATION OF SINTERING REQUIREMENTS}

Several simple algorithms for reaction energies calculations ${ }^{[33]}$ allow the theoretical evaluation of the required atmosphere composition at every sintering 
stage for preventing manganese alloyed steels from oxidation. Evaluation of the required sintering atmosphere composition on the base of standard free-energy calculations were carried out using a thermodynamic software package Outotech HSC Chemistry 6.1 (Outotec Research Oy, Pori, Finland). Calculations were performed for the oxidation/reduction reactions of the oxides located on the base powder surface as they have the highest influence on the resulting mechanical properties. Carbon was considered pure nondissolved graphite admixed to the base powder. According to these considerations, the activities of surface oxides and carbon can be taken as unity. However, this simplification is only valid during the heating stage, when surface oxides and condensed manganese oxide actually have to be removed.

As the most stable oxide in the system is $\mathrm{MnO}$, thermodynamic requirements, calculated for the reduction of this oxide, will meet the thermodynamic requirements for less stable iron oxides. If $\mathrm{FeO}$ and $\mathrm{MnO}$ are reduced by solid carbon, then the maximum pressures of active gases that can be tolerated in the system can be calculated by considering free enthalpy changes $\Delta G_{0}$ at absolute temperature $T$. At the temperature $1393 \mathrm{~K}$ $\left(1120{ }^{\circ} \mathrm{C}\right)$, at which the sintering of samples was carried out, the first reaction that has to be considered is dissociation of the oxide as follows:

$$
\mathrm{MnO}=\mathrm{Mn}+0.5 \mathrm{O}_{2}
$$

Because $\Delta G_{T}^{0}=\Delta H-T \Delta S$ and $\Delta G_{T}^{0}=-R T \ln K_{p}$ from the HSC Chemistry 6.1 database, the free-energy changes and equilibrium constants for reaction [1] are $\Delta G_{1393}^{0}=281,945 \mathrm{~J}$ and $K_{p}=2.679 \times 10^{-11}$, respectively. Then, for the following reaction:

$$
K_{p}=P\left(\mathrm{O}_{2}\right)^{1 / 2} \rightarrow P\left(\mathrm{O}_{2}\right)=K_{p}^{2}=7.18 \times 10^{-22}(\text { bar })
$$

If it is considered that carbon is reducing $\mathrm{MnO}$ to form $\mathrm{Mn}+\mathrm{CO}$, then the pertinent reaction is as follows:

$$
\mathrm{MnO}+\mathrm{C}=\mathrm{Mn}+\mathrm{CO}
$$

For reaction [2], $\Delta G_{1393}^{0}=47,372 \mathrm{~J}$ and $K_{p}=1.674 \times$ $10^{-2}$.

Because $K_{p}=P(\mathrm{CO}) \rightarrow \mathrm{P}(\mathrm{CO})=1.674 \times 10^{-2}$ (bar).

Thus, the $\mathrm{CO}$ pressure must be less than 0.01674 bar for the reduction of $\mathrm{MnO}$ to proceed spontaneously at $1393 \mathrm{~K}\left(1120^{\circ} \mathrm{C}\right)$.

If $\mathrm{CO}$ is in equilibrium with $\mathrm{C}$ and $\mathrm{CO}_{2}$ as follows:

$$
\mathrm{C}+\mathrm{CO}_{2}=2 \mathrm{CO}
$$

then the maximum allowed pressure of carbon dioxide in the system can be evaluated. For reaction [3], $\Delta G_{1393}^{0}=-72,943 \mathrm{~J}$, for which $K_{p}=543.5$ and $K_{p} \stackrel{=}{=}(\mathrm{CO})^{2} / P\left(\mathrm{CO}_{2}\right)$ as follows:

$$
\begin{aligned}
P\left(\mathrm{CO}_{2}\right) & =P(\mathrm{CO})^{2} / K_{p}=(0.01674)^{2} / 543.5 \\
& =5.16 \times 10^{-7} \text { (bar) }
\end{aligned}
$$

Considering that $\mathrm{CO}$ and $\mathrm{CO}_{2}$ are in equilibrium, oxygen partial pressure also can be evaluated via the following equilibrium reaction:

$$
2 \mathrm{CO}+\mathrm{O}_{2}=2 \mathrm{CO}_{2}
$$

For reaction [4], $\Delta G_{1393}^{0}=-323,258 \mathrm{~J}$, for which $K_{p}=1.322 \times 10^{12}$, and

$$
\begin{aligned}
K_{p} & =P\left(\mathrm{CO}_{2}\right)^{2} /\left[P(\mathrm{CO})^{2} \times P\left(\mathrm{O}_{2}\right)\right] \rightarrow P\left(\mathrm{O}_{2}\right) \\
& =P\left(\mathrm{CO}_{2}\right)^{2} /\left[K_{p} \times P(\mathrm{CO})^{2}\right]=7.18 \times 10^{-22}(\text { bar })
\end{aligned}
$$

So, $P\left(\mathrm{O}_{2}\right)=7.18 \times 10^{-22}$ bar, which is in full agreement with reaction [1] for oxide dissociation.

These calculations show that at $1393 \mathrm{~K}\left(1120^{\circ} \mathrm{C}\right)$ for $\mathrm{MnO}, \mathrm{Mn}$, and $\mathrm{C}$ to be in equilibrium with a gaseous atmosphere, this atmosphere must be of the following composition:

$$
\begin{aligned}
& P(\mathrm{CO})=1.674 \times 10^{-2} \text { bar } \\
& P\left(\mathrm{CO}_{2}\right)=5.16 \times 10^{-7} \text { bar } \\
& P\left(\mathrm{O}_{2}\right)=7.18 \times 10^{-22} \text { bar }
\end{aligned}
$$

If sintering is performed in atmosphere of composition 90 pet $\mathrm{N}_{2} / 10$ pet $\mathrm{H}_{2}$, then at $1393 \mathrm{~K}\left(1120{ }^{\circ} \mathrm{C}\right)$, the following reaction occurs:

$$
\mathrm{C}+\mathrm{H}_{2} \mathrm{O}=\mathrm{CO}+\mathrm{H}_{2}
$$

From the HSC Chemistry 6.1 database for reaction [5], $\Delta G_{1393}^{0}=-63,857 \mathrm{~J}$ and $K_{p}=248$, respectively. Then, for the following reaction:

$$
\begin{aligned}
K_{p} & =\left[P(\mathrm{CO}) \times P\left(\mathrm{H}_{2}\right)\right] / P\left(\mathrm{H}_{2} \mathrm{O}\right) \rightarrow P\left(\mathrm{H}_{2} \mathrm{O}\right) \\
& =\left[P(\mathrm{CO}) \times P\left(\mathrm{H}_{2}\right)\right] / K_{p}=6.75 \times 10^{-6}(\text { bar })
\end{aligned}
$$

Water partial pressure $P\left(\mathrm{H}_{2} \mathrm{O}\right)=6.75 \times 10^{-6}$ bar corresponds to a dew point near $210 \mathrm{~K}\left(-63^{\circ} \mathrm{C}\right)$. This finding points to the fact that a dew point lower than $210 \mathrm{~K}\left(-63^{\circ} \mathrm{C}\right)$ is required for proper sintering of manganese-containing steels in the 90 pct $\mathrm{N}_{2} / 10$ pct $\mathrm{H}_{2}$ atmosphere at $1393 \mathrm{~K}\left(1120{ }^{\circ} \mathrm{C}\right)$. Applying the same methodology, the equilibrium pressures of active gases at $1473 \mathrm{~K}\left(1200{ }^{\circ} \mathrm{C}\right)$ for the same system are as follows:

$$
\begin{gathered}
P(\mathrm{CO})=6.09 \times 10^{-2} \mathrm{bar} \\
P\left(\mathrm{CO}_{2}\right)=3.13 \times 10^{-6} \mathrm{bar} \\
P\left(\mathrm{O}_{2}\right)=2.79 \times 10^{-20} \mathrm{bar} \\
P\left(\mathrm{H}_{2} \mathrm{O}\right)=1.3 \times 10^{-5} \operatorname{bar}\left(\mathrm{DP} \approx 215 \mathrm{~K}\left(-58^{\circ} \mathrm{C}\right)\right)
\end{gathered}
$$

Atmosphere purity according to the calculated requirements was used in all experiments. It is important to state that the prealloyed powder does not have such strict requirements to the atmosphere purity because of the much lower manganese activity in the prealloyed state. 


\section{EXPERIMENTAL PROCEDURE}

Three different powder mixtures with the same manganese content of $0.8 \mathrm{wt}$ pct were prepared on the base of two different kinds of water-atomized steel powders produced by Höganäs AB (Höganäs, Sweden). Nominal compositions of the base powders are given in Table I.

The base powder was admixed with $0.5 \mathrm{wt}$ pct natural graphite (Kropfmühl UF4) and 0.8 wt pct lubricant (amide wax). Additionally, $0.5 \mathrm{wt}$ pct $\mathrm{Mn}$ was admixed to powder $C$ to obtain $0.8 \mathrm{wt}$ pet $\mathrm{Mn}$ in total. The materials' compositions and designations are presented in Table II. For the manganese carrier in the alloy CEM, high-purity electrolytic manganese powder (99.89 $\mathrm{Mn}, 0.007 \mathrm{C}, 0.076 \mathrm{Si}-\mathrm{Fe}-\mathrm{Se}, 0.0013 \mathrm{P}$, and $0.018 \mathrm{~S}$ [wt pct]) was used (Erachem Comilog). Medium carbon ferromanganese powder $(81.39 \mathrm{Mn}, 1.48 \mathrm{C}, 0.29 \mathrm{Si}, 0.17$ $\mathrm{P}$, and $0.01 \mathrm{~S}$ [wt pct]), which was also obtained from Erachem Comilog, was used as the Mn carrier in the alloy CFM. Both kinds of manganese carrier powder were sieved, and the size fraction below $45 \mu \mathrm{m}$ was used for powder mixture preparation. The powder mixtures were homogenized in a Turbula mixer for 15 minutes prior to subsequent processing.

For interrupted sintering trials, cylindrical specimens $\left(\varnothing 10 \times 12 \mathrm{~mm}^{3}\right)$ were pressed uniaxially at $600 \mathrm{MPa}$ to a green density of $\sim 7 \mathrm{~g} \times \mathrm{cm}^{-3}$. The specimens were sintered in a laboratory tube furnace LAC "LHR A-type." The specimens were heated slowly $\left(10 \mathrm{~K} \times \mathrm{min}^{-1}\right)$ to the sintering temperature of $1393 \mathrm{~K}$ $\left(1120{ }^{\circ} \mathrm{C}\right)$ or $1473 \mathrm{~K}\left(1200{ }^{\circ} \mathrm{C}\right)$, dwelled for 30 minutes, and then cooled with the cooling rate of 10 or $50 \mathrm{~K} \times \mathrm{min}^{-1}$ to room temperature. All samples subjected to interrupted heating trials were cooled at $50 \mathrm{~K} \times \min ^{-1}$. The specimens also were held at $\sim 623 \mathrm{~K}\left(350{ }^{\circ} \mathrm{C}\right)$ for 15 minutes for delubrication purposes during the heating stage. Sintering was performed in 10 pet $\mathrm{H}_{2} / 90$ pet $\mathrm{N}_{2}$ (purity 5.0) atmosphere with an inlet dew point in the range $218 \mathrm{~K} / 213 \mathrm{~K}\left(-55^{\circ} \mathrm{C} /\right.$ $-60{ }^{\circ} \mathrm{C}$ ) during all experiments according to the aforementioned thermodynamic calculations. The flow rate was $\sim 81 \times \min ^{-1}\left(1.3 * 10^{-4} \mathrm{~m}^{3} \times \mathrm{s}^{-1}\right)$, which corresponded to $\sim 0.1 \mathrm{~m} \mathrm{x} \mathrm{s}^{-1}$ for the furnace tube diameter used. A high flow rate and a high ratio of sintering atmosphere/specimen in the sintering furnace secure a high purity of sintering atmosphere during processing

Table I. Nominal Chemical Composition of Base Powder Used (Weight Percent)

\begin{tabular}{lcccc}
\hline Powder & $\mathrm{Mn}$ & $\mathrm{Cr}$ & $\mathrm{O}$ & $\mathrm{S}$ \\
\hline $\mathrm{C}$ & 0.3 & 0.02 & 0.16 & 0.005 \\
$\mathrm{D}$ & 0.8 & 0.14 & 0.08 & 0.007 \\
\hline
\end{tabular}

that was confirmed by atmosphere monitoring inside the container with the specimens for some materials. ${ }^{[20]}$ The specimens that were cooled at $10 \mathrm{~K} \times \min ^{-1}$ were sintered at a lower atmosphere purity with dew point $\sim 233 \mathrm{~K}\left(-40^{\circ} \mathrm{C}\right)$ at the furnace outlet. The specimens were sampled from the furnace during the heating stage at defined temperatures (Figure 2). The temperature profiles, presented in Figure 2, were measured in situ by a thermocouple in one of the samples.

The first numbers for the specimen designations indicate the sampling temperatures. The presence of a second number indicates the sintering time (without second number, the sintering time was 1 minute), and the third number shows the cooling rate. For example, CFM1120/30/10 means alloy CFM (Table II), sintered at $1393 \mathrm{~K}\left(1120^{\circ} \mathrm{C}\right)$ for 30 minutes, and cooled at $10 \mathrm{~K} / \mathrm{min}$. Sampling temperatures were chosen according to the results of dilatometry experiments for the base powders. ${ }^{[20]}$ The first sampling temperature was chosen with the aim to be close to but below the $\alpha-\gamma$-transformation in the ferrite region (i.e., $1023 \mathrm{~K}\left(750{ }^{\circ} \mathrm{C}\right)$ and $1013 \mathrm{~K}\left(740{ }^{\circ} \mathrm{C}\right)$ for the systems on the base of powders $C$ and $D$, respectively). The second temperature was chosen to be close but above the $\alpha-\gamma$-transformation in the austenite region (i.e., $1098 \mathrm{~K}\left[825^{\circ} \mathrm{C}\right]$ and $1083 \mathrm{~K}$ $\left[810^{\circ} \mathrm{C}\right]$ for the systems on the base of powders $C$ and $D$, respectively). To study the influence of the manganese sublimation effect on the behavior of the material admixed with ferromanganese, the specimens also were sampled in the low-temperature region at $993 \mathrm{~K}$ $\left(720^{\circ} \mathrm{C}\right)$ and $1033 \mathrm{~K}\left(760{ }^{\circ} \mathrm{C}\right)$, as shown in Figure 2.

The microstructure examination was performed on the longitudinal section of cylindrical specimens using

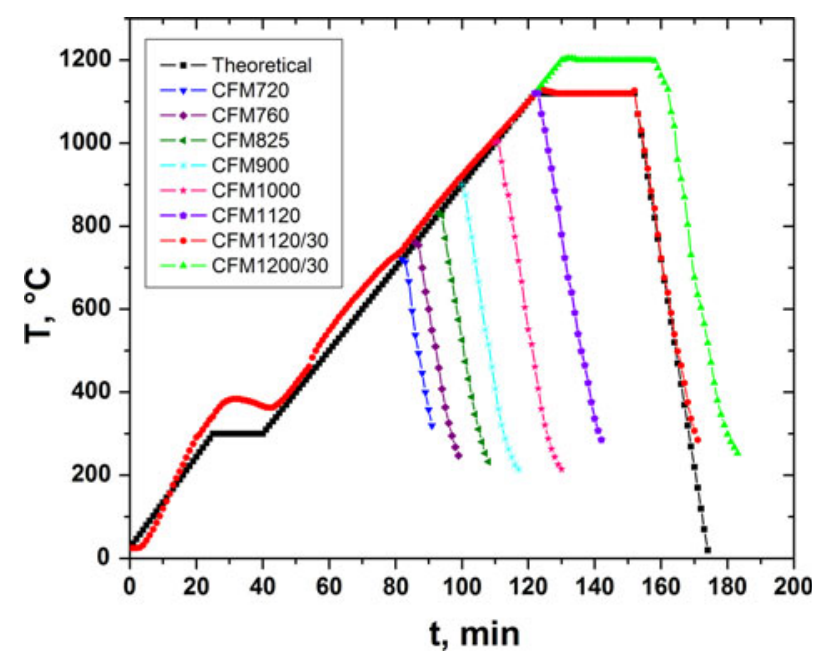

Fig. 2-Thermoprofile used during interrupted sintering experiments for the CFM alloy.

Table II. Studied Materials with Their Designation Codes and Nominal Compositions (Weight Percent)

\begin{tabular}{lllr}
\hline Material Code & \multicolumn{1}{c}{ Mixture Composition } & Mn Carrier & Alloy Composition \\
\hline CEM & C $+0.5 \mathrm{Mn}+0.5 \mathrm{C}+0.8 \mathrm{AW}$ & Electrolytic Mn & Fe- $0.8 \mathrm{Mn}-0.5 \mathrm{C}$ \\
CFM & $\mathrm{C}+0.5 \mathrm{Mn}+0.5 \mathrm{C}+0.8 \mathrm{AW}$ & FeMn & Fe-0.8Mn-0.5C \\
D & $\mathrm{D}+0.5 \mathrm{C}+0.8 \mathrm{AW}$ & Prealloyed & Fe- $0.8 \mathrm{Mn}-0.5 \mathrm{C}$ \\
\hline
\end{tabular}


light optical microscope Olympus GX71 (Olympus Corporation, Tokyo, Japan). Nital-picral etchant (1 vol pet of $\mathrm{HNO}_{3}+2 \mathrm{wt}$ pct of picric acid in ethanol) was used for etching. Characterization of the fracture surface was performed on the specimens after "button" (tensile) test using high-resolution scanning electron microscope (HR-SEM) JEOL JSM-7000F (JEOL Ltd., Tokyo, Japan) and LEO Gemini 1550 (LEO GmbH, Oberkochen, Germany), equipped with energy dispersive X-ray spectrometer (EDX) INCX-sight (Oxford Instruments Ltd., High Wycombe, UK). Specimens for the "button" test were machined by means of the electro-spark method from sintered cylindrical samples $\left(\varnothing 10 \times 12 \mathrm{~mm}^{3}\right)$ as described in Reference 20 . The rupture strength of such machined samples was obtained using the "button" (tensile) test on a ZWICK 1387 machine at a crosshead speed of $0.1 \mathrm{~mm} \times \mathrm{min}^{-1}$. Surface chemical analysis by means of X-ray photoelectron spectroscopy (PHI 5500 - Perkin Elmer Corporation, Eden Praine, MN) was carried out on the fracture surfaces of specimens of sintered samples. These specimens were prepared by dry machining to final dimensions $(4 \mathrm{~mm} \times 4 \mathrm{~mm} \times 10 \mathrm{~mm})$, cleaned, and inserted into an ultrahigh vacuum fracture facility and then fractured (bending) in an ultrahigh vacuum prior to X-ray photoelectron spectroscopy (XPS) analysis. The analyzed area in XPS analysis was about $0.8 \mathrm{~mm}$ in diameter. The determination of the oxygen content was performed using LECO TC-336 (LECO Corporation, St. Joseph, MI), and the carbon content was estimated by volumetric method using a Ströhlein apparatus.

\section{RESULTS}

\section{A. Chemical Analysis}

Results of the carbon and oxygen analysis of specimens after interrupted sintering experiments are presented in Figures 3 and 4, respectively. The strong correlation between oxygen and carbon content in the specimens is evident. The higher oxygen content for both admixed specimens ( 2 to 3 times higher than for prealloyed one!) emphasize the critical importance of oxidation of the samples during heating stage, as also was demonstrated by the thermoanalytical studies. ${ }^{[20]}$ Another interesting result is the much higher oxygen content and higher carbon loss for the slow-cooled specimens-CFM1120/30/10 and D1120/30/10. The higher carbon loss values of these specimens also is caused by lower atmosphere purity (higher dew point) for these specimens, which causes higher oxidation during heating and further reduction of these oxides by carbon. Much lower carbon loss is evident for prealloyed material during all stages.

\section{B. Rupture Strength}

Because of the small size of the sintered specimens, the only possibility to obtain some mechanical properties for comparison of different alloys and describe development (strength) of interparticle connections was the use of the "button" tensile test, described in Reference 20. Results in terms of rupture strength show much higher values at all temperatures for prealloyed specimens in comparison with admixed ones (Figure 5). The lowest rupture strength values were obtained for the material admixed with high-purity electrolytic manganese (CEM alloy) even in comparison with the material containing more contaminated ferromanganese (CFM alloy). In fact, the value of rupture strength for the CEM alloy after high-temperature sintering at $1473 \mathrm{~K}\left(1200{ }^{\circ} \mathrm{C}\right)$ is also lower than that obtained for prealloyed material (D alloy) just before sintering at $1393 \mathrm{~K}\left(1120^{\circ} \mathrm{C}\right)$ (1 minute sintering time).

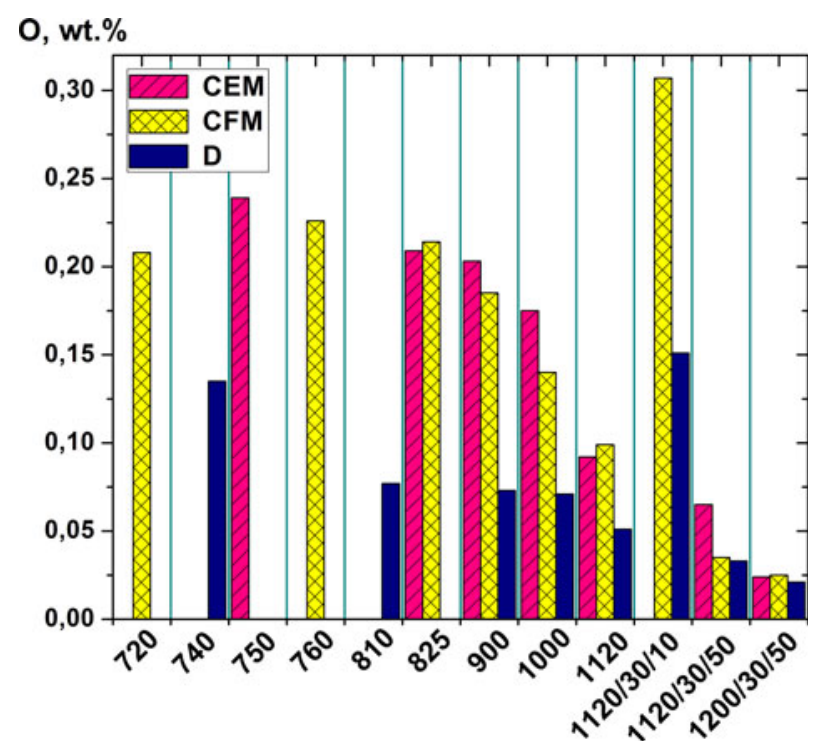

Fig. 3-Oxygen content for the CEM, CFM, and D systems.

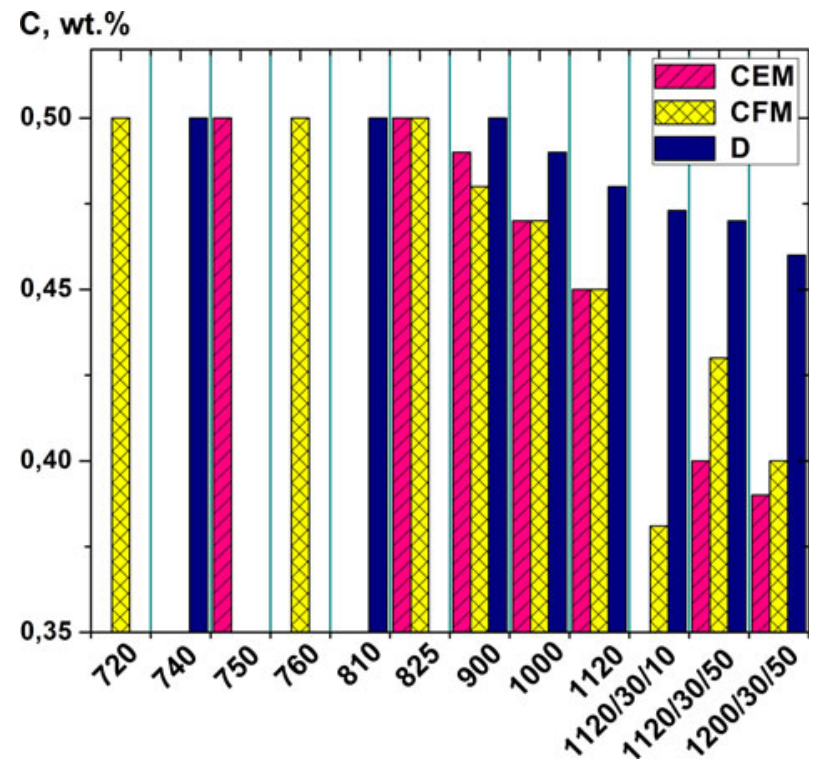

Fig. 4 - Carbon content for the CEM, CFM, and D systems. 


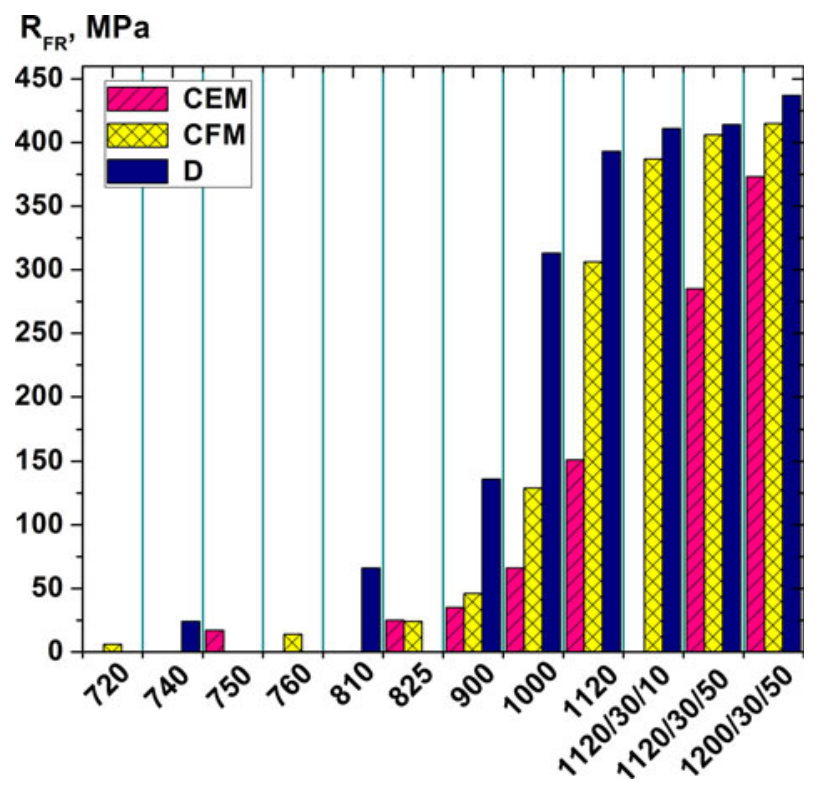

Fig. 5-Rupture strength value for the CEM, CFM, and D alloys.

\section{Microstructure Observations}

\section{CEM Alloy}

Figure 6 shows the microstructures of the samples from different sintering stages of the CEM alloy with admixed electrolytic manganese. A pronounced microstructure heterogeneity is observed for all specimens. The microstructure consists mostly of ferrite and pearlite in various amounts. For the first sampled specimens (CEM750, CEM825, and CEM900), the microstructure basically consists of only ferrite. However, austenitic rims with thicknesses of up to $2 \mu \mathrm{m}$ and $4 \mu \mathrm{m}$ around manganese carrier particles were registered for samples taken at $1023 \mathrm{~K}\left(750{ }^{\circ} \mathrm{C}\right)$ and at $1098 \mathrm{~K}\left(825^{\circ} \mathrm{C}\right)$, respectively. These observed rims indicate a rather pronounced manganese dissolution in the iron matrix. Some coarse pearlite on the grain boundaries near the powder surfaces, extending up to $10 \mu \mathrm{m}$, was registered at $1098 \mathrm{~K}\left(825^{\circ} \mathrm{C}\right)$. In a sample taken at $1173 \mathrm{~K}$ $\left(900{ }^{\circ} \mathrm{C}\right)$, the thickness of the "rims" around the electrolytic manganese particles is approximately $5 \mu \mathrm{m}$. The pearlite is now also finer, and its portion is $\sim 5$ pct to 10 pct. Further temperature increase leads to a final

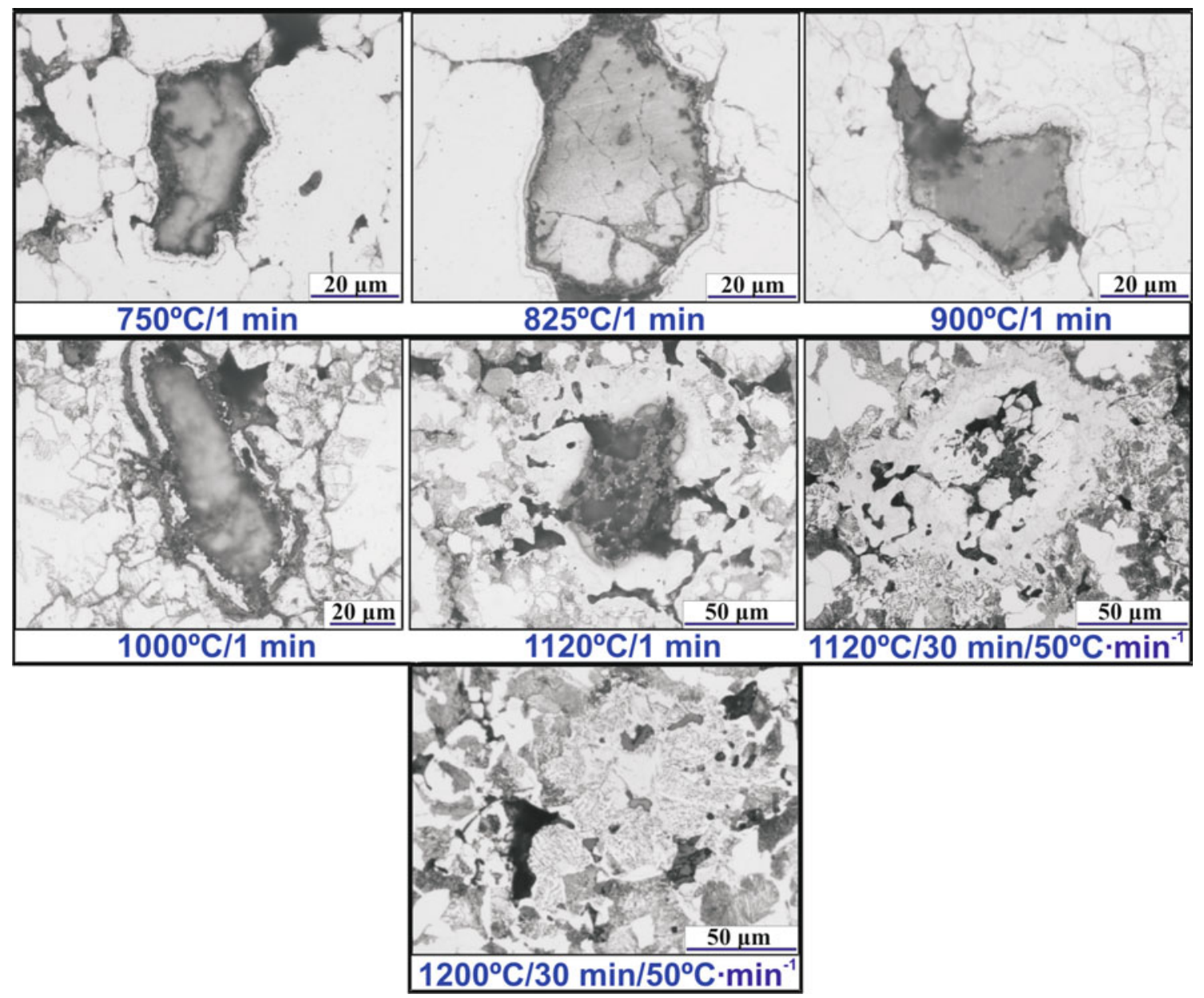

Fig. 6-Microstructure development during sintering of the CEM alloy (Fe-0.8Mn-0.5C admixed with electrolytic Mn). 
pearlite portion increasing and extending the "rims" around manganese particles up to $8 \mu \mathrm{m}$ is shown for the CEM1000 specimen. The admixed electrolytic manganese particles can be observed for the sample held at up to $1273 \mathrm{~K}\left(1000{ }^{\circ} \mathrm{C}\right)$. Nevertheless, at the beginning of the sinter holding at $1393 \mathrm{~K}\left(1120{ }^{\circ} \mathrm{C}\right)$, manganese carrier residues are not present anymore and leave only large pores behind filled by contaminants. Thus, the electrolytic manganese particles have disappeared during heating to the sintering temperature. The resulting microstructure consists of ferrite and a fine pearlite, the portion of which is about $20 \mathrm{vol}$ pct. The complicated sequence of microstructure constituents around manganese residues (austenite that changes to martensite and a mixture of upper and lower bainite and pearlite at larger distances from the manganese carrier particles) first was observed in the material heated to the sinter holding temperature. This sequence extended up to $10 \mu \mathrm{m}$ to $15 \mu \mathrm{m}$ into the iron matrix. The microstructure after sintering at $1393 \mathrm{~K}\left(1120{ }^{\circ} \mathrm{C}\right)$ for 30 minutes indicates a more improved manganese dissolution. This improvement is evident from the larger austenite-martensite region around $\mathrm{Mn}$ residuals $(15 \mu \mathrm{m}$ to $20 \mu \mathrm{m})$ and a more fine ferrite-carbide mixture that changes this region and has almost the same extension. However, ferrite is still prevailing (above 60 pct). Specimens sintered at a higher temperature, CEM1200/30/50, showed a higher portion of pearlite $(>60 \mathrm{pct})$. The much better manganese dissolution then results in a more homogeneous microstructure; the austenitemartensite region stretches out only up to $5 \mu \mathrm{m}$ to $10 \mu \mathrm{m}$, but the extension of the bainite region is much greater-up to $50 \mu \mathrm{m}$ - which then is exchanged for a pearlitic microstructure. The size of large pores is controlled by the size of admixed electrolytic manganese particles, and it decreases with sintering temperature and with increasing time. However, even after hightemperature sintering, rather large pores (up to $20 \mu \mathrm{m}$ ) filled with contaminants are observed.

\section{CFM Alloy}

The same microstructure heterogeneity as for the CEM alloy is characteristic for the CFM alloy (admixed with ferromanganese alloy) for all temperatures (Figure 7). The microstructure development includes the same features as the admixed with the electrolytic manganese system. Preferentially, a ferritic microstructure is observed in material processed up to $1173 \mathrm{~K}$ $\left(900{ }^{\circ} \mathrm{C}\right)$. A pearlite formation on the particle boundaries first was observed in material processed at $1098 \mathrm{~K}$

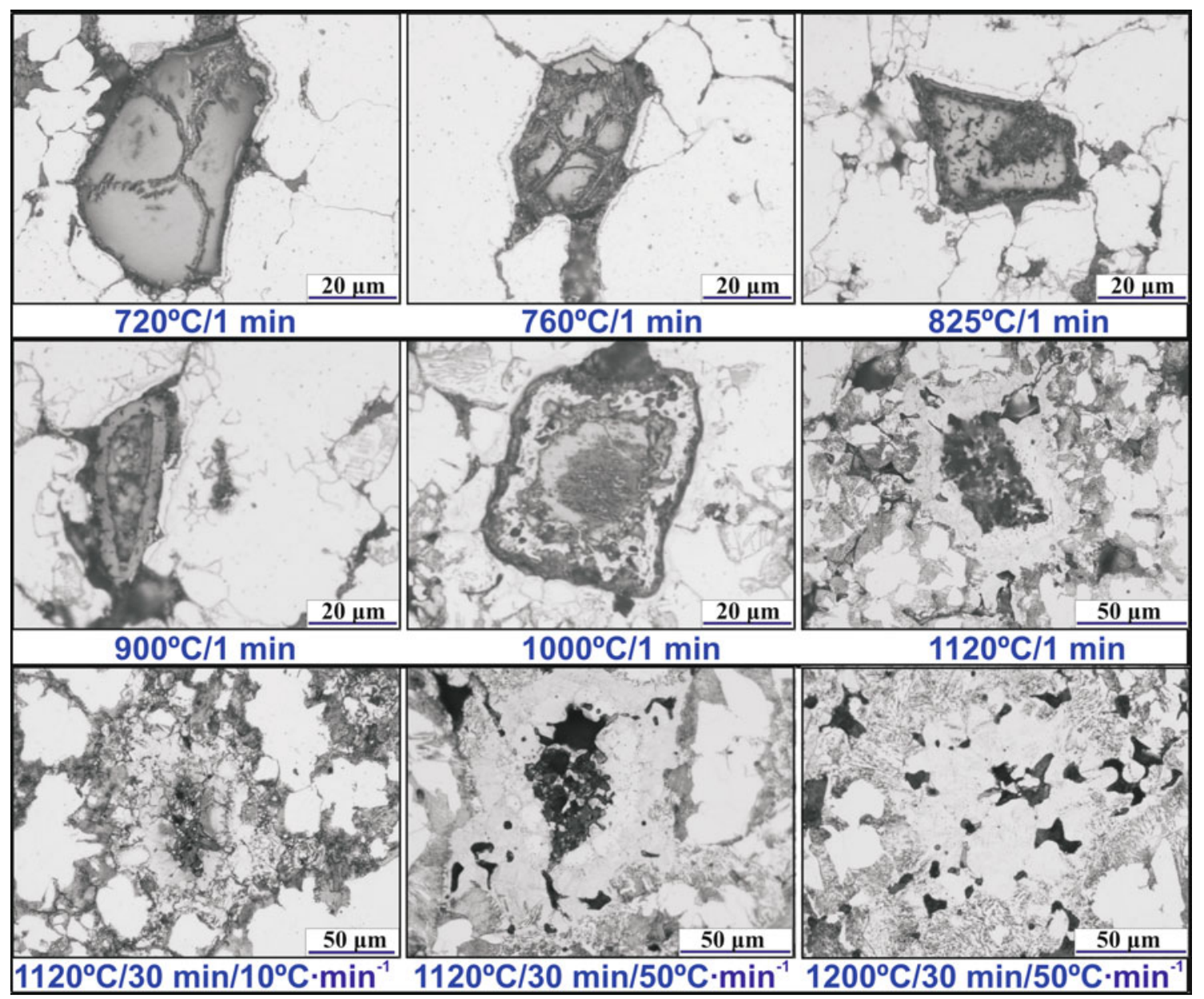

Fig. 7-Microstructure development during sintering of the CFM alloy (Fe-0.8Mn-0.5C admixed with FeMn). 
$\left(825^{\circ} \mathrm{C}\right.$ ). The main difference between CEM and CFM alloys is the thickness of the austenitic rims around the manganese carrier particles; the thickness of this rim is up to two times smaller for the material admixed with the ferromanganese system. This indicates a lower rate of manganese solution in the iron matrix, which in turn, results in a more heterogeneous microstructure as shown in Figures 6 and 7. Ferromanganese particles are present up to the sintering temperature. An austenite-martensitebainite-pearlite mixture first is shown at the beginning of sintering ( 1 minute at $1393 \mathrm{~K}\left[1120{ }^{\circ} \mathrm{C}\right.$ ) and extends up to $10 \mu \mathrm{m}$ to $12 \mu \mathrm{m}$ into the original iron particles. After sintering for 30 minutes at the same temperature, a pronounced manganese dissolution in the iron matrix is evident resulting in an extension of the austenite-martensite-bainite mixture up to $20 \mu \mathrm{m}$ followed by a more extended pearlite region. The core of the prior particles is still fully ferritic. A pronounced difference between slow- and fast-cooled specimens, CFM1120/30/10 and CFM1120/30/50, respectively, is elucidated in a surprisingly lower portion of pearlite in the slow-cooled specimen. This difference is attributed to the lower as-sintered carbon content of the slowcooled specimen, as shown in Figure 4. This is the result of higher carbon loss during the more oxidizing conditions during slow cooling of CFM1120/30/10. Oxidation of the slow-cooled specimen, especially close to the edges, clearly was observed on nonetched cross-section metallographic specimens. After sintering at $1473 \mathrm{~K}$ $\left(1200{ }^{\circ} \mathrm{C}\right)$, ferrite and pearlite portions are nearly equal (however, they are lower than in CEM1200/30/50). Around ferromanganese residues, the bainitic microstructure is prevailing and extending up to $50 \mu \mathrm{m}$ into the original iron particles with a small amount of austenite-martensite mixture in adjoining areas to residues. The bainitic areas pass into outer pearlitic rims around ferromanganese residues. Large pores after the manganese carrier particles were observed filled with a higher amount of contaminants in the material with ferromanganese than in the material with electrolytic manganese.

One important feature of both admixed systems is the presence of "chains" of oxide particles that "pierce" the base iron particles in areas adjoining manganese residuals. These oxide particles start to appear clearly in material processed close to the sintering temperature and are more pronounced for admixed with electrolytic manganese specimens. The oxide particles are expected to have a negative impact on the strength of the sintered specimens, which is discussed subsequently.

\section{D Alloy}

The microstructure development and its final state for the prealloyed material differs significantly from the admixed systems with the same nominal chemical composition and processing conditions (Figure 8). Even the first sampled specimen D740 shows a higher purity and the presence of some pearlite close to the edges of the original particles. This observation indicates much faster carbon diffusion in this system in comparison with the admixed ones. In material sampled at $1083 \mathrm{~K}$ $\left(810^{\circ} \mathrm{C}\right)$, pearlite extends up to $10 \mu \mathrm{m}$ into the original iron particles; a comparable amount and distribution of the pearlite for the admixed systems was observed only after processing at $1173 \mathrm{~K}\left(900{ }^{\circ} \mathrm{C}\right)$. The microstructure of the D900 sample consists of evenly distributed fine pearlite in the iron matrix with a portion of up to 20 pct. Such a pronounced carbon diffusion and distribution effect was observed in the admixed systems only for samples processed at the sintering temperature. Further temperature increasing leads to the pearlite portion increasing ( $30 \mathrm{pct}$ to $35 \mathrm{pct}$ after processing at $1273 \mathrm{~K}$ $\left[1000{ }^{\circ} \mathrm{C}\right]$ and about $40 \mathrm{pct}$ after processing at $1393 \mathrm{~K}$ $\left[1120^{\circ} \mathrm{C}\right]$ ); such an effect was observed for the admixed specimens only after they had been sintered at $1393 \mathrm{~K}$ $\left(1120{ }^{\circ} \mathrm{C}\right)$ for 30 minutes. Sintering of the prealloyed material at $1393 \mathrm{~K}\left(1120{ }^{\circ} \mathrm{C}\right)$ for 30 minutes then results in an evenly distributed ferrite-pearlite mixture in which fine pearlite is prevailing, and its portion is up to $55 \mathrm{pct}$ to $60 \mathrm{pct}$ higher than for any sintered samples of the admixed systems. A higher oxidation of the slow-cooled specimen D1120/30/10 was registered as well. A somewhat lower amount of pearlite resulting from carbon loss and coarser pearlite also was found for the slowcooled D1120/30/10 compared with the fast-cooled D1120/30/50 samples (Figure 8). The material sintered at a higher temperature (D1200/30/50) shows a ferritepearlite microstructure comparable with that of the D1120/30/50 material. Another important distinguishing characteristic of this prealloyed specimen is the much smaller, more rounded, and pure pores in comparison with those of the admixed ones.

\section{Fractography}

\section{CEM Alloy}

For the CEM alloy, the fracture surfaces are rough for the specimens sampled at $1023 \mathrm{~K}\left(750{ }^{\circ} \mathrm{C}\right), 1098 \mathrm{~K}$ $\left(825^{\circ} \mathrm{C}\right)$, and $1173 \mathrm{~K}\left(900{ }^{\circ} \mathrm{C}\right)$ (Figure 9). The individual particles or their agglomerates can be distinguished easily, the connection between particles only begins to develop, and steps of ductile point and line fracture can be observed for the CEM750 specimen. A more developed network of branched lines associated with ductile fracture is evident for processing at an increasing temperature. In some sites, ductile fracture with large dimples, initiated by the cementitic lamellae of coarse pearlite, was observed for the specimen sampled at $1098 \mathrm{~K}\left(825^{\circ} \mathrm{C}\right)$. After $1173 \mathrm{~K}\left(900{ }^{\circ} \mathrm{C}\right)$, interparticle ductile dimple fracture initiated by point inclusions, bridge porosity, and cementitic lamellae is the main micromechanism of failure. The proportional dependence of the amount of interparticles necks on temperature is registered; then a considerable increase in rupture strength also occurs with increasing temperature (Figure 5). The portion of fractured particle necks on the fracture surfaces is dependent on purity of the prior particles surface, which is a prerequisite to obtain metallic contacts between the particles. Even a visual observation of the first sampled specimen (CEM750) indicates high oxidation, especially in the areas around the manganese carrier particle (Figure 9). A temperature increase leads to an improved purity of the base iron powder surfaces; however, much stronger surface 


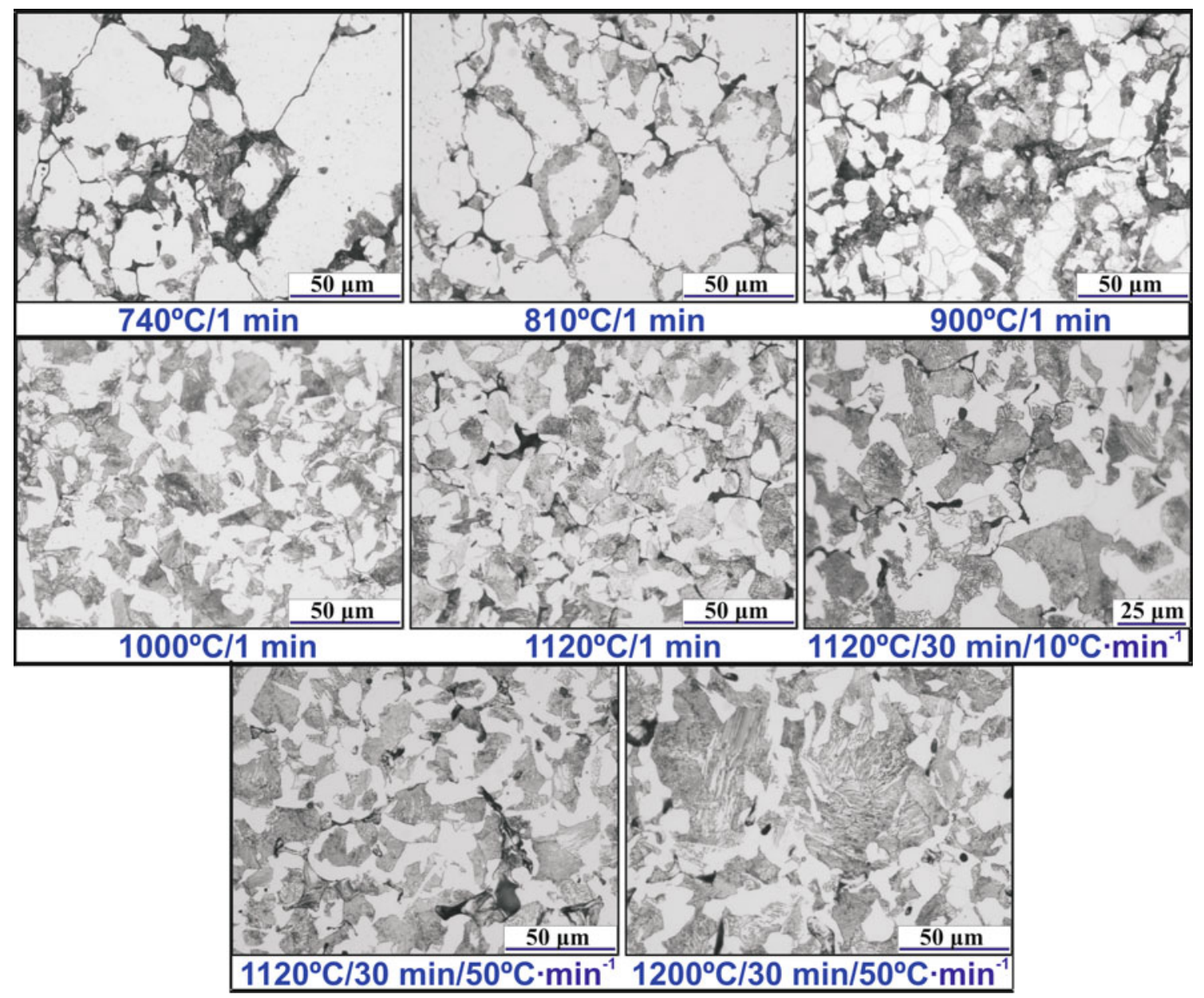

Fig. 8-Microstructure development during sintering of the D alloy ( $\mathrm{Fe}-0.8 \mathrm{Mn}-0.5 \mathrm{C}$ prealloyed).

contamination is observed for particles adjoining electrolytic manganese particles. Thus, a much lower amount (if any) of interparticle connections is observed close to the electrolytic manganese particle. At the beginning of sintering (CEM1120 specimen), much better connections between the particles are developed, especially around the electrolytic manganese particles, and these are improved further during the proceeding sintering (CEM1120/30/50 specimen). Intergranular decohesion facets around manganese carrier particles first were registered after processing at $1273 \mathrm{~K}$ $\left(1000{ }^{\circ} \mathrm{C}\right)$, and they were observed in large amounts in the sintered specimen CEM1120/30/50. Hightemperature sintering results in a decreasing amount of intergranular decohesion facets and in an increasing in portion of transgranular cleavage facets.

\section{CFM Alloy}

Regarding the CFM alloy, the fracture surfaces of the first three sampled specimens (CFM 720, CFM760, and CFM825) have a similar appearance; a connection between particles only begins to develop, and steps of ductile line fracture with very small lines can be observed in some places (Figure 10). The base iron particles around ferromanganese particles also are covered by contaminants. Nevertheless, the extension of the contaminated region around the ferromanganese residues is smaller compared with that for the CEM alloy (Figures 9 and 10). This means much better interparticle necks development in the regions surrounding ferromanganese particles, leading to stronger material. Enhancement of the rupture strength value for the CFM1000 specimen in comparison with that of the CFM900 sample corresponds to about a three-times increase (Figure 8). This increase is caused by much better connections between particles; an interparticle dimple ductile fracture with shallow dimples is prevailing here, as is shown in Figure 10. A small fraction of intergranular decohesion facets close to ferromanganese residues also first was observed in the sample processed at this temperature. One important fact to affirm for the CFM1000 specimen is the appearance of small grains in the base matrix particles around an FeMn particle (grain size $<5 \mu \mathrm{m}$ ), where intergranular decohesion facets also were observed. The temperature increase obviously leads to a much higher portion of fine grains around the ferromanganese residue. The grain boundaries of these small grains are degraded significantly because of the precipitation of secondary phase particles on them, which results in a considerable amount of 

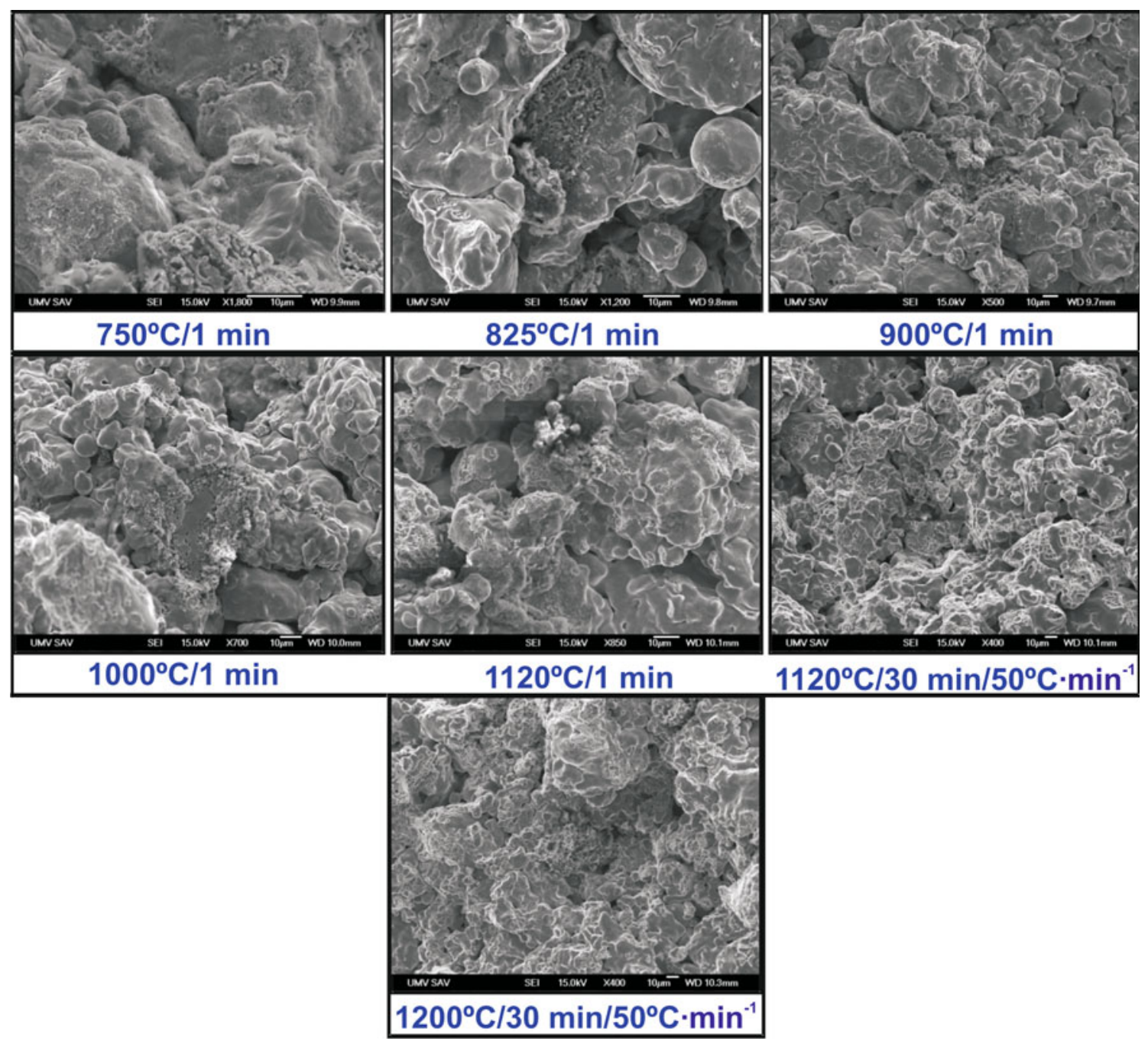

Fig. 9-Fracture surface of interrupted sintered specimens of CEM alloy (Fe-0.8Mn-0.5C admixed with electrolytic Mn).

intergranular decohesion facets on the fracture surface. Specimens kept at the sinter holding temperatures $\left(1393 \mathrm{~K}\left[1120^{\circ} \mathrm{C}\right]\right.$ and $\left.1473 \mathrm{~K}\left[1200{ }^{\circ} \mathrm{C}\right]\right)$ are considerably purer in comparison with those sampled during the heating stage. A ductile interparticle fracture with good pronounced lines and dimples of different size, initiated by bridge porosity and nonreduced refractory oxides on the prior particles surfaces, is prevailing here. Transgranular cleavage facets are registered as well, the amount of which increases with an increasing sintering temperature. The zones around the ferromanganese residue still are surrounded by intergranular decohesion facets. The slowly cooled specimen CFM1120/30/10 differs from the faster cooled one by a much stronger oxidation inside pores and of the zones surrounding ferromanganese residues. A characteristic feature of this specimen is the much higher portion of the intergranular decohesion facets around the ferromanganese residues. A much lower contamination of the iron particle surfaces around manganese carrier residuals separates the specimen sintered at $1473 \mathrm{~K}\left(1200{ }^{\circ} \mathrm{C}\right)$ from the other ones, especially the samples with admixed electrolytic manganese.

\section{D Alloy}

As for the admixed systems, a high fracture surface roughness was observed for the D alloy specimens kept at lower temperatures (D740 and D810) as well (Figure 11). However, already at low temperatures around $1013 \mathrm{~K}\left(740{ }^{\circ} \mathrm{C}\right)$, sintering is significant enough to ensure that a good pronounced point and line ductile fracture is observed. The specimens also seem more pure than the admixed ones processed at the lower temperatures. Remaining surface oxide still can be observed. After processing at $1083 \mathrm{~K}\left(810{ }^{\circ} \mathrm{C}\right)$, the surface oxide layer is almost fully removed, which results in much more developed interparticle connections. Dimple ductile fracture with nice pronounced small dimples, initiated by cementitic lamellae, is the dominant fracture mechanism of the $\mathrm{D}$ alloy specimens processed at $1173 \mathrm{~K}\left(900{ }^{\circ} \mathrm{C}\right)$. Some rare residuals of surface oxide with a size up to $5 \mu \mathrm{m}$ still are observed. The temperature increase leads to an improved overall purity as well because of decreased amount and size of particulate features inside interparticle necks. For the D1120 specimen, some amount of transparticle transgranular cleavage along cementite lamellae was 


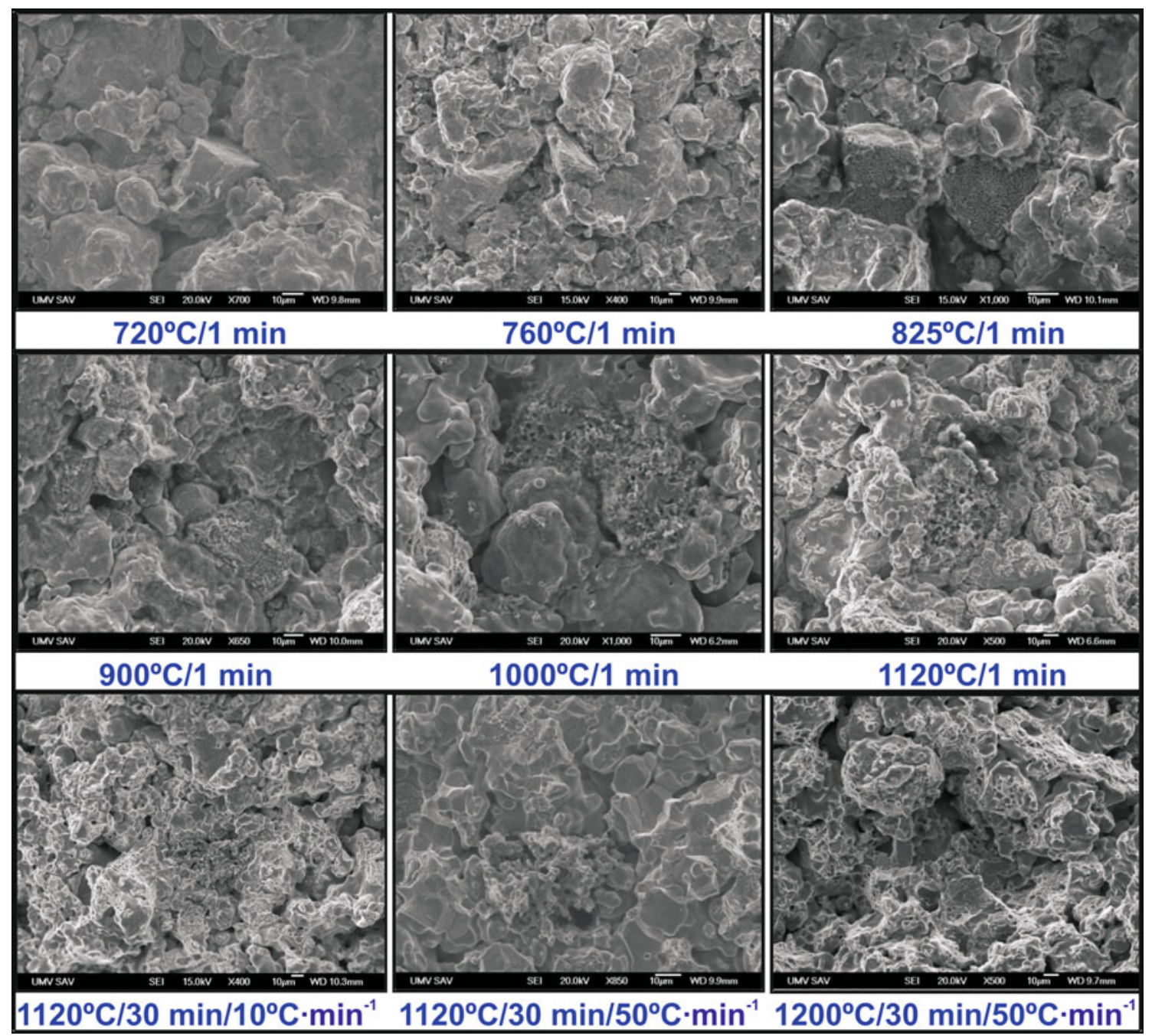

Fig. 10-Fracture surface of interrupted sintered specimens of the CFM alloy (Fe-0.8Mn-0.5C admixed with FeMn).

registered. For sintered specimens, interparticle ductile failure otherwise prevails, although a higher amount of cleavage facets is observed. The slowly cooled specimen $\mathrm{D} 1120 / 30 / 10$ is more oxidized as is evident from a higher portion of particulate features located on free particle surfaces on the fracture surfaces. For the D alloy specimen sintered at $1473 \mathrm{~K}\left(1200{ }^{\circ} \mathrm{C}\right)$, only very few fine inclusions can be found on the fracture surface. Clearly, at all temperatures, fully prealloyed material D shows a much better fracture surface purity with more developed interparticle necks. This finding correlates well with the much higher rupture strength value for this alloy for all processing temperatures (Figure 5).

\section{E. SEM and EDX Analysis}

HR SEM imaging combined with X-ray microanalysis of particulate inclusions on the fracture surface of all interrupted sintered specimens was performed. To achieve representative data, three to five sites of interest were analyzed for every specimen with approximately six points of interest in each case. Examples of SEM + EDX analyses for some of the specimens are presented in Figure 12. Analysis for the sintered specimens of the CFM alloy is presented elsewhere in more detail..$^{[21]}$ Results of these analyses indicate that the contaminant features observed around manganese carrier residues are manganese oxide particles for both CEM and CFM materials after processing at all temperatures. Manganese carrier residues for both admixed alloys are formed mostly by manganese oxide. However, for ferromanganese, a high content of silicon is registered as well. After sintering, especially at a high temperature, together with an essential decrease in size of manganese residues, the oxygen content decreases as well, whereas a higher sulfur content is registered. Considering the admixed materials, the presence of sulfur can be related to the fact that both manganese carriers used constitute a sulfur source. The same tendency of sulfur enrichment in particulate features after high-temperature sintering was observed for prealloyed material D as well (Figure 12). Clearly, sulfur segregation from inside the base powder 

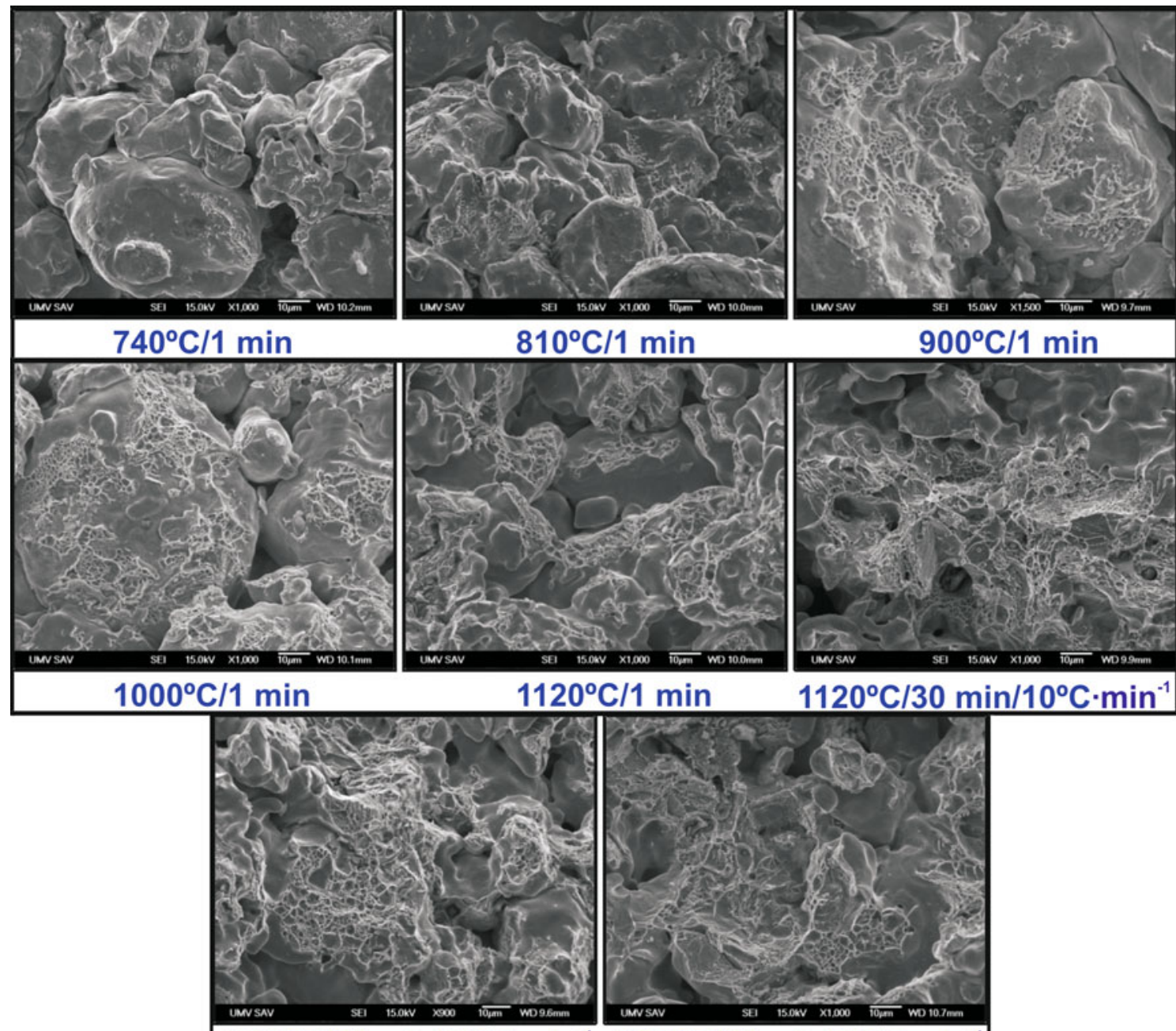

$1120^{\circ} \mathrm{C} / 1 \mathrm{~min}$

$1120^{\circ} \mathrm{C} / 30 \mathrm{~min} / 10^{\circ} \mathrm{C} \cdot \mathrm{min}^{-1}$

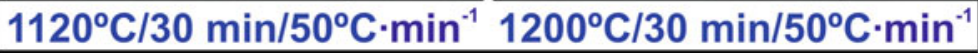

Fig. 11-Fracture surface of interrupted sintered specimens of the D alloy (Fe- $0.8 \mathrm{Mn}-0.5 \mathrm{C}$ prealloyed).

is a plausible mechanism. Another source for sulfur can be graphite. Different kinds of graphite have different levels of trace sulfur that could lead to surface enrichment in sulfur as graphite is consumed because of the dissolution of carbon in the iron matrix. At low temperatures, particulate features observed inside interparticle necks on the fracture surface of the prealloyed material specimens have a spherical shape and a size of up to $1 \mu \mathrm{m}$. These particulate features are formed preferably by manganese oxides with traces of chromium and silicon oxides. A temperature increase leads to a considerable decrease in the amount and size of these observed particulates. However, a tendency for them to coalescence or cluster to one another is observed close to the sintering temperature. After being processing at $1273 \mathrm{~K}\left(1000{ }^{\circ} \mathrm{C}\right)$, the $\mathrm{D}$ alloy sample shows on its fracture surface manganese sulfide in the form of particulate inclusions. The manganese sulfide become the main component of the particulate features after sintering at $1393 \mathrm{~K}\left(1120^{\circ} \mathrm{C}\right)$ or higher if good sintering conditions are applied. Traces of chromium (supposed to be connected to oxygen in oxide) disappear after the sintering, indicating its reduction from complex oxide, whereas silicon enrichment is still evident, suggesting the presence of silicon oxide.

\section{F. XPS Analysis}

The apparent concentrations and distribution in depth of the elements present on the fracture surface as well as their chemical state were determined by means of intermittent XPS analysis and ion etching (argon). The XPS survey spectra, recorded at different etch depth from the fracture surfaces of specimens of material with admixed electrolytic manganese and ferromanganese, sintered at $1473 \mathrm{~K}\left(1200^{\circ} \mathrm{C}\right)$, are shown in Figure 13. The analyses indicate that no significant difference exists in the surface composition between the two alloys. The XPS spectra show strong iron $(\mathrm{Fe} 2 \mathrm{p})$ peak, oxygen $(\mathrm{O} 1 \mathrm{~s})$, and manganese (Mn2p). Carbon (C1s) was found on the surface as well and is connected with the absorbed species. Apart from these elements, traces of sulfur (S2p) were registered in the CFM material. The XPS analyses indicate slightly higher manganese and 

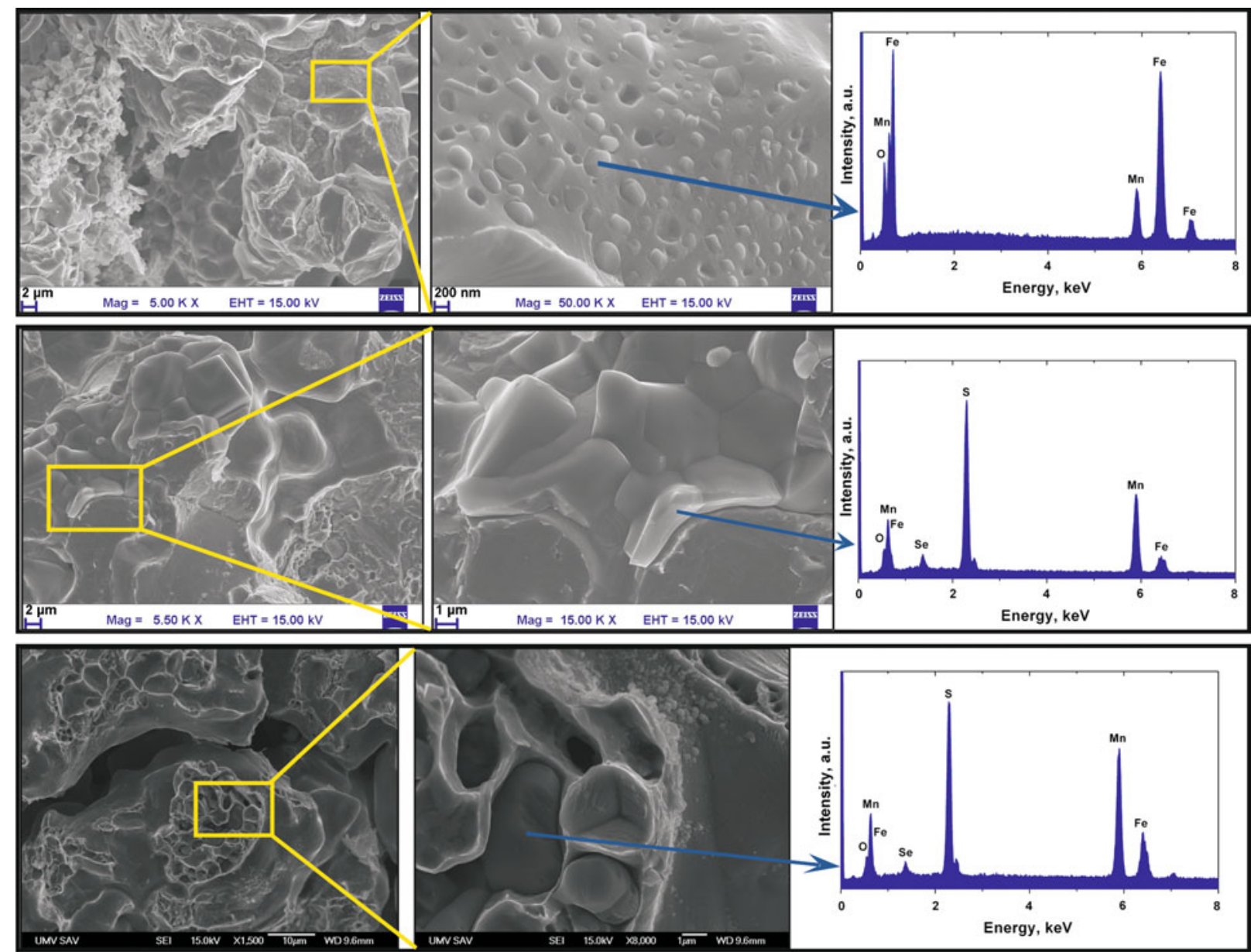

Fig. 12-SEM + EDX analysis of particulate features observed on the fracture surface of interrupted sintered specimens CEM1120/30/50 (top), CEM1200/30/50 (middle), and D1120/30/50 (bottom).
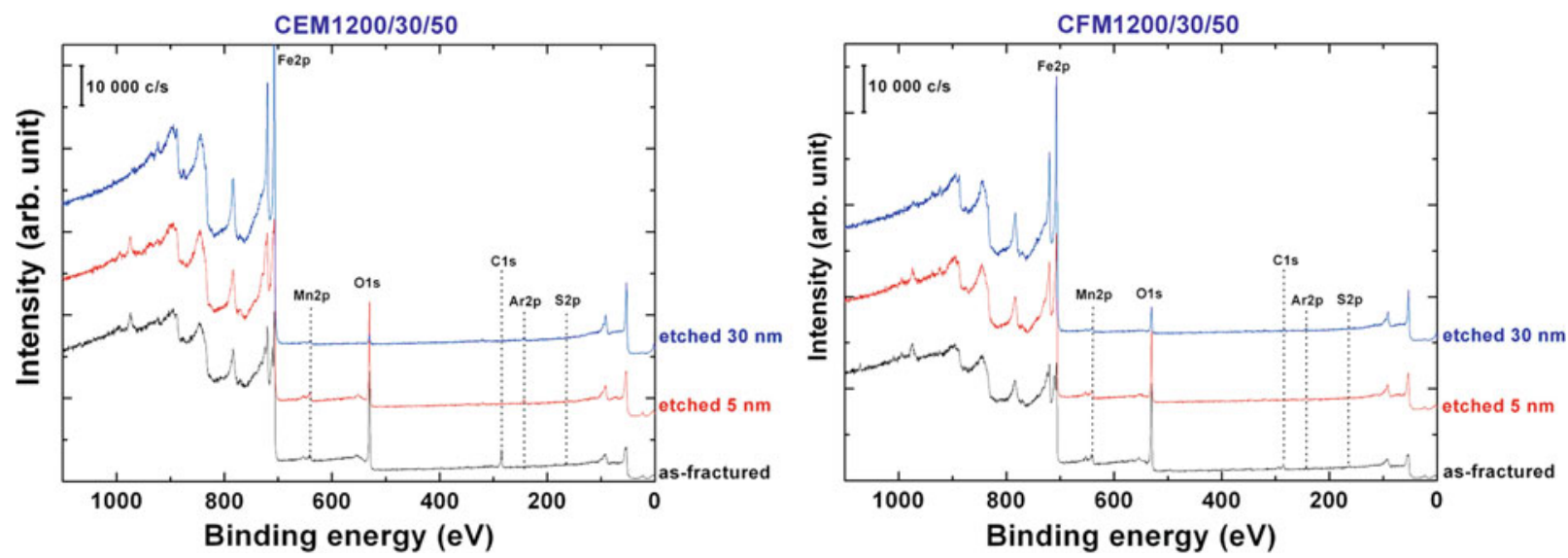

Fig. 13-XPS survey scan of fracture surface of specimens CEM1200/30/50 (left) and CFM1200/30/50 (right), respectively.

oxygen contents for the specimen CFM1200/30/50 admixed with ferromanganese in comparison with the specimen admixed with electrolytic manganese as shown in Figure 14. Narrow scans with high-energy resolution (Figure 15) show that close to the surface manganese is present in a chemical compound state (oxide and/or sulfide) for both cases. At large etch depths, contribution from metallic manganese is registered and is more pronounced in the CEM material. The sulfur peak is evident at small etch depths for the CFM specimen, but it is below the detection limit for the CEM material. This finding suggests a higher amount of oxides/sulfides 
present on the fracture surface of the specimen admixed with ferromanganese material because of larger ferromanganese residues after high-temperature sintering. Some data concerning XPS analysis of the CFM alloy at a lower sintering temperature are presented elsewhere. ${ }^{[21]}$

\section{DISCUSSION}

A chemical analysis of the specimens sampled during the heating stage indicates that several differences exist in the processes that occur in a differently alloyed system. A much higher oxygen content for admixed specimens at around $973 \mathrm{~K}\left(700^{\circ} \mathrm{C}\right)$ to $1073 \mathrm{~K}\left(800{ }^{\circ} \mathrm{C}\right)$ (Figure 3 ) in comparison with the initial oxygen content of the base powder (Table I) indicate the specimens' oxidation even during heating in such dry atmospheres. It is important to emphasize that specimens were sintered in a hydrogen-containing atmosphere, and around 50 pct of the total oxygen content in the powder is the surface-bound oxygen related to the iron oxide layer on the surface of the powder, as it was shown

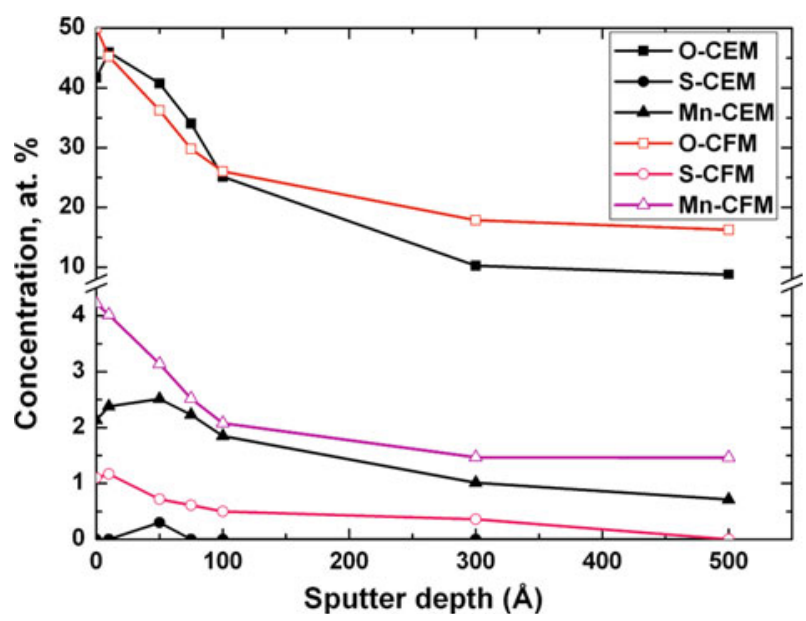

Fig. 14-XPS analysis of fracture surface of specimens CEM1200/ 30/50 and CFM1200/30/50.

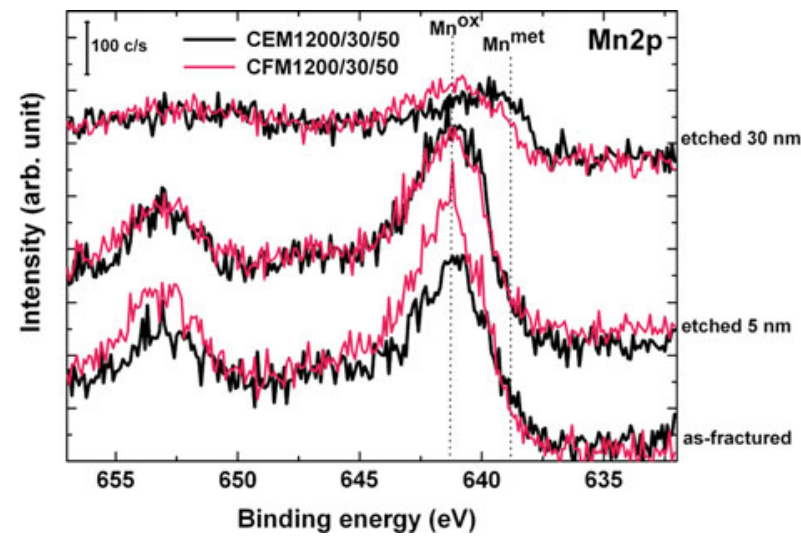

recently for powders studied in Reference 29, a large part of which is removed by hydrogen at a lower temperature. The result is decreased oxygen content. Oxidation related to the products of lubricant decomposition also was minimized by low-temperature lubricant removal. A direct carbothermal reduction of surface oxides by graphite also is thermodynamically feasible in this temperature range and has a peak at $\sim 923 \mathrm{~K}\left(650^{\circ} \mathrm{C}\right)$ and $\sim 943 \mathrm{~K}\left(670{ }^{\circ} \mathrm{C}\right)$ for the base powders $\mathrm{C}$ and $\mathrm{D}$, respectively. ${ }^{[29]} \mathrm{A}$ higher intensity of carbothermal reduction with increasing temperature is supposed as a minimum to stop further oxidation of the specimens, which, however, was not observed. Comparison of oxygen content for specimens admixed with electrolytic manganese and ferromanganese powder reveals one more detail: oxygen content is higher for material admixed with electrolytic manganese. Increasing oxygen content was indicated in the narrow range of temperatures between $993 \mathrm{~K}\left(720{ }^{\circ} \mathrm{C}\right)$ and $1033 \mathrm{~K}$ $\left(760{ }^{\circ} \mathrm{C}\right)$ for material admixed with ferromanganese. This behavior of oxygen content for admixed systems can be easily understandable when taking into account manganese sublimation that becomes substantial in this temperature interval as well, especially from electrolytic manganese. Evaporated manganese reacts with water vapor produced by the reduction of surface oxides at this temperature interval and with oxygen from the sintering atmosphere, which jointly lead to such a high oxygen content. The manganese oxide formed in this way has considerably higher stability in comparison with the oxides present on the initial surface of the base powder. ${ }^{[29]}$ This finding is evident in the changes in oxygen content during the heating stage; a considerable drop occurs in the oxygen content from $1013 \mathrm{~K}\left(740{ }^{\circ} \mathrm{C}\right)$ to $1083 \mathrm{~K}\left(810{ }^{\circ} \mathrm{C}\right)$ for prealloyed material resulting from the reduction of surface iron and iron-containing spinel oxides. Another decrease in oxygen is observed after heating to above $1273 \mathrm{~K}\left(1000{ }^{\circ} \mathrm{C}\right)$, when more stable surface manganese-containing oxides partially are reduced. For the admixed specimens, this tendency is fully different: the drop in oxygen content was observed only after heating to above $1373 \mathrm{~K}\left(1100{ }^{\circ} \mathrm{C}\right)$ (close to the sintering temperature), even if a larger amount of surface iron oxide is characteristic for base powder $\mathrm{C}$ in

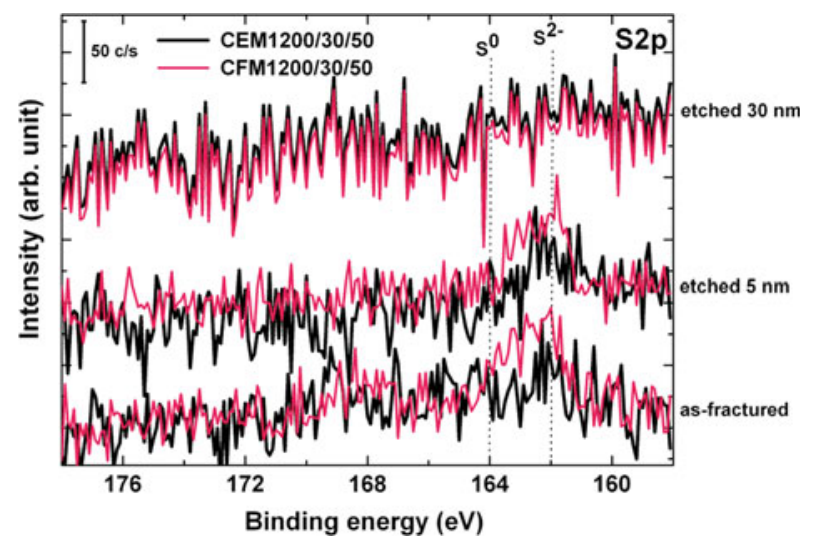

Fig. 15-XPS narrow scans of Mn2p and S2p peaks on the fracture surface of specimens CEM1200/30/50 and CFM1200/30/50. 
comparison with that of D. ${ }^{[29]}$ This result indicates that most of the oxides present in the admixed specimens after starting the Mn sublimation are Mn-containing surface oxides. This finding was confirmed by SEM + EDX analysis. Much faster carbon dissolution confirms the hypothesis of a more efficiently removed surface oxide layer, as the first steps of the pearlite were observed even at $1013 \mathrm{~K}\left(740{ }^{\circ} \mathrm{C}\right)$ for the prealloyed material, whereas for admixed materials, the first pearlite formation was indicated around $1098 \mathrm{~K}$ $\left(825^{\circ} \mathrm{C}\right)$. Evenly distributed pearlite then was obtained already at $1173 \mathrm{~K}\left(900{ }^{\circ} \mathrm{C}\right)$ for $\mathrm{D}$ materials, whereas such a microstructure only could be produced at the sintering temperature $\left(1393 \mathrm{~K}\left[1120^{\circ} \mathrm{C}\right]\right)$ for both admixed systems. Of course, the Mn-stabilizing effect on the austenite promotes carbon dissolution, as was shown in Reference 34; however, the difference between measured $\alpha-\gamma$-transformation temperatures for base powders $\mathrm{C}$ and $\mathrm{D}^{[20]}$ is rather low-1062 $\mathrm{K}\left(789{ }^{\circ} \mathrm{C}\right)$ and $1050 \mathrm{~K}\left(777^{\circ} \mathrm{C}\right)$, respectively - which is unlikely to influence the onset of carbon dissolution significantly.

The efficiency of a surface oxide layer reduction can be elucidated on the fracture surface as the temperature range of appearance and further development of interparticle necks. Pronounced point and line connections between the particles together with a higher purity of initial powder surface, which was observed for material heated at $1013 \mathrm{~K}\left(740{ }^{\circ} \mathrm{C}\right)$, clearly indicate the onset of interparticle necks development (Figure 11). Subsequent improvement in surface oxides removal with temperature by carbothermal reduction and improved activity of interparticle diffusion processes results in dimple ductile fracture already at $1173 \mathrm{~K}\left(900{ }^{\circ} \mathrm{C}\right)$. In both admixed systems, a similar kind of ductile point and line fracture were observed for samples being processed at around $1173 \mathrm{~K}\left(900{ }^{\circ} \mathrm{C}\right)$ but only between the iron particles that were not adjacent to manganese carrier particles (Figures 9 and 10). No connections between the particles were observed around manganese carrier residues in material processed at lower temperatures for both admixed specimens. The reason for this is the presence of manganese oxide layer formed by the oxidation of sublimated manganese close to the carrier particles (Figure 16). Hence, as in the case of prealloyed material, the surface of the base powder is clean after processing at around $1173 \mathrm{~K}\left(900^{\circ} \mathrm{C}\right)$, indicating the removal of the surface oxide layer and allowing interparticle necks to develop. However, manganese carrier particles and adjoining steel particles become more oxidized. So, the "shift" of oxidation to manganese carrier particles is evident, which is shown in the fact that the oxygen content stays the same during the heating stage for both admixed systems. The extension of the contaminated region around manganese carrier particles is higher for system with admixed electrolytic manganese. This zone increases with temperature, and at about $1273 \mathrm{~K}$ $\left(1000{ }^{\circ} \mathrm{C}\right.$ ), it reaches around $100 \mu \mathrm{m}$ depending on the surrounding pores structure. Considering the high purity of the sintering atmosphere applied, when conditions inside pores enable the reduction of manganese oxide at above $1373 \mathrm{~K}\left(1100{ }^{\circ} \mathrm{C}\right)$ (close to sintering temperature), the contaminated areas decrease in size,

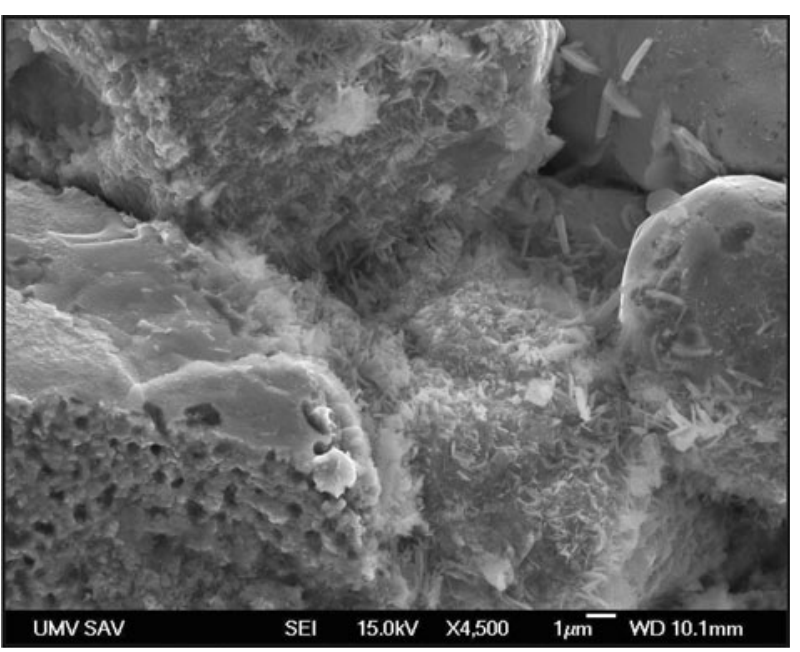

Fig. 16-Fragment of base powder particle surface close to manganese carrier covered by particulate features in the CFM alloy at $1098 \mathrm{~K}\left(825^{\circ} \mathrm{C}\right)$.

and intensive interparticle connection growth starts around the manganese carriers. This effect of course is reflected in the strength of the heated compacts; there is a considerable increase in rupture strength for admixed materials when raising the processing temperature from $1273 \mathrm{~K}\left(1000{ }^{\circ} \mathrm{C}\right)$ to $1393 \mathrm{~K}\left(1120^{\circ} \mathrm{C}\right)$. The large increase in compact strength for the material with admixed ferromanganese in comparison with the material with added electrolytic manganese confirms the existence of larger contaminated areas around the manganese carrier particles. After sintering at $1393 \mathrm{~K}$ $\left(1120^{\circ} \mathrm{C}\right)$, the oxygen content and the strength of the prealloyed and admixed with ferromanganese materials are comparable. It is important to emphasize the high atmosphere purity applied in the experiments performed. Such purity is nearly impossible to reach in industrial conditions. Sintering at industrial atmosphere purity leads to a more intensive oxidation of the admixed materials with a harmful effect on mechanical properties. ${ }^{[21]}$ However, for the CEM material, considerable oxygen reduction was observed only after hightemperature sintering, and still, the rupture strength value was lower in comparison with the other two materials. As revealed by HR SEM, the reason for this behavior is connected with the enclosure of condensed manganese oxide inside interparticle necks next to manganese carrier particles during the heating stage. The larger extension of contaminated areas around electrolytic manganese residue leads to a higher amount of enclosed manganese-containing oxides, the reduction of which is kinetically much slower than that of oxides in the pores. The enclosed manganese oxide is reduced partially only during high-temperature sintering, which results in more extended defect areas with weak interparticle connections.

The presence of manganese carrier particles during the whole heating stage up to $1393 \mathrm{~K}\left(1120{ }^{\circ} \mathrm{C}\right)$ is another confirmation of their intensive oxidation, which counteracts the otherwise expected scenario of rapid manganese redistribution via the gas phase. Considering also 
the low heating rate of $10 \mathrm{~K} \times \mathrm{min}^{-1}$ and the high manganese sublimation, the presence of manganese carrier particles at high temperatures is not expected. Slower evaporation of $\mathrm{Mn}$ in ferromanganese in comparison with the electrolytic manganese is more likely connected with the presence of carbides $\left(\mathrm{M}_{3} \mathrm{C}\right)$ that lower the Mn activity. However, the lowering of manganese activity seems to be more pronounced than expected based only on the presence of carbides. The theoretical and experimental evaluation of behavior of manganese carrier particles is addressed separately in Reference 35.

It is important to emphasize that the positive effect of hydrogen in the sintering atmosphere and the delubrication at low temperatures means the removal of oxide products (because of surface iron oxides reduction and lubricant decomposition) before intensive manganese sublimation. The typical industrial process when a lubricant is removed at $\sim 973 \mathrm{~K}\left(600{ }^{\circ} \mathrm{C}\right)$ or higher leads to a more significant oxidation of admixed materials. ${ }^{[20]}$ A heating rate increase at medium temperatures $(973 \mathrm{~K}$ $\left[700{ }^{\circ} \mathrm{C}\right.$ ] to $\left.1273 \mathrm{~K}\left[1000{ }^{\circ} \mathrm{C}\right]\right)$ to pass faster region of intensive manganese sublimation to minimize manganese vapor oxidation is suggested. However, too rapid heating close to the sintering temperature will result in a massive enclosing of condensed manganese oxides inside interparticle necks, which is harmful for the resulting mechanical properties.

An important issue connected with admixed manganese PM steels, widely debated during last decades, is the brittleness of such admixed steels, which is the main obstacle for their industrial use. Several hypotheses have been proposed, connected with brittleness caused by microstructure heterogeneity, size of manganese carrier particles, their residue, and their oxidation. ${ }^{[13-17]} \mathrm{A}$ pernicious influence of oxide phases on the mechanical properties was hypothesized in Reference 17, and the completely brittle behavior associated with predominantly intergranular type failure caused by the oxide phase at grain boundaries was assumed in References 13 and 14 for high manganese and low carbon content. However, locations and extension of oxide phases, their composition, as well as their influence was not understood clearly. In recent studies of defect areas by HR
SEM + EDX, Auger, and XPS ${ }^{[20,21]}$ clearly indicate that the brittleness of material containing admixed manganese is caused by the weakness of grain boundaries within the base matrix particles around the manganese carrier residuals. Intergranular decohesion failure around manganese carrier particles is inherent in admixed manganese PM steels and is caused by the presence of complex oxides and manganese sulfide on the intergranular decohesion facets. ${ }^{[20,21]}$ The presented results of HR SEM + EDX and XPS analyses, presented in Figures 12 through 15, shows a higher amount of manganese and oxygen together with higher sulfur in the material admixed with ferromanganese after high-temperature sintering. This is due to the presence of $\mathrm{MnS}$ from the ferromanganese residues. This assumes better fracture surface purity for the specimen admixed with electrolytic manganese because of a pronounced reduction of manganese oxides at the applied conditions. However, detailed analysis of the fracture surface indicates the preferable location of the contaminants inside ferromanganese residues (pores), whereas a higher amount of oxides and sulfides on the intergranular decohesion facets was registered for material admixed with electrolytic manganese. Such residual intergranular brittleness is nearly fully removed for material admixed with ferromanganese after hightemperature sintering but still is observed for CEM material that, together with a more extended contaminated area, results in lower final mechanical properties. Summarizing the results from SEM + EDX analyses in Figures 12 through 15 and presented in Reference 21, it can be concluded that composition, morphology, and location of the contaminants after sintering is dictated by the type of manganese carrier used and the sintering conditions (temperature profile, sintering atmosphere purity, etc.). High-temperature sintering with a good atmosphere purity (DP $<218 \mathrm{~K}\left[-55^{\circ} \mathrm{C}\right]$ ) results in an almost full reduction of oxides, and residual contamination is formed by manganese sulfide located on free powder surface (pores). This kind of contamination has no detrimental effect on mechanical properties. Lower sintering temperature and/or lower quality sintering atmospheres lead to a higher oxidation of admixed
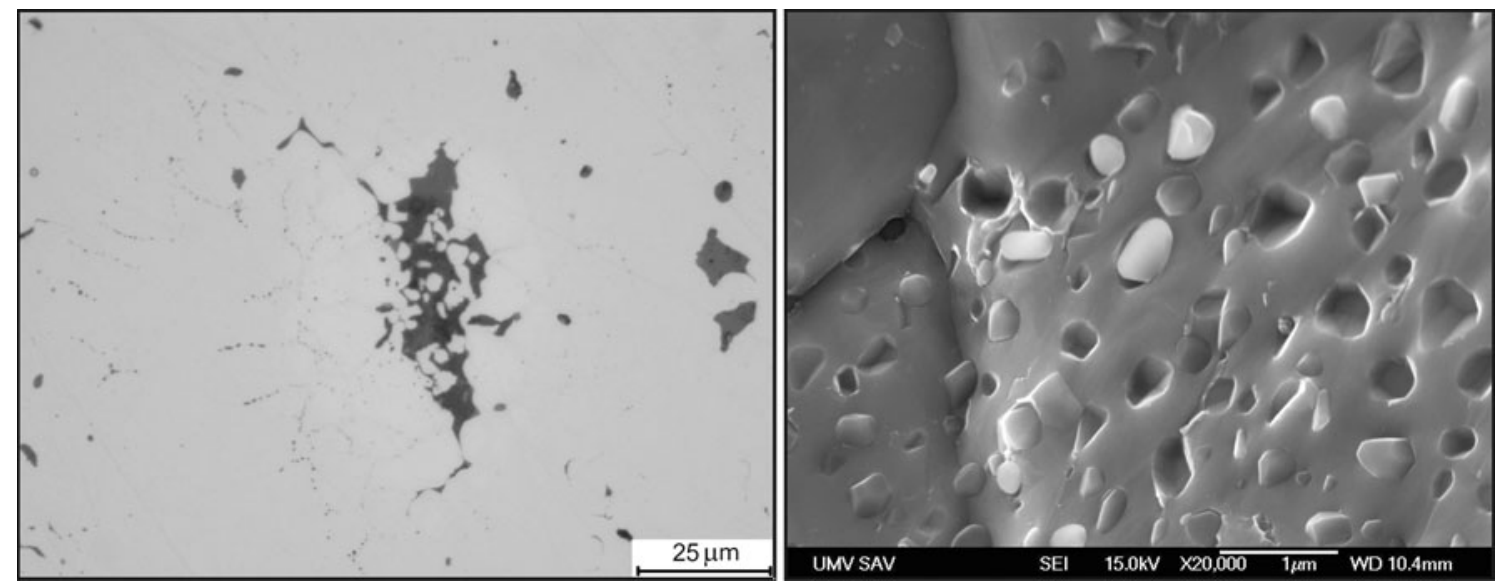

Fig. 17-Point oxides networks around manganese carrier residue in CFM1120/30/10: cross-section of samples in as-polished state (left) and SEM image showing the appearance of fine oxides on the intergranular decohesion facets (right). 
material during processing. The result is a brittle structure resulting from grain boundary degradation around manganese carriers. The mechanism of grain boundary degradation and its evolution during sintering is described in detail elsewhere. ${ }^{[35]}$

Degraded grain boundaries around manganese residuals are shown on the unetched microstructure as well as the "chains" of point oxides (Figure 17) that develop close to the sintering temperature. The networks of point oxides are more pronounced for materials with electrolytic manganese, which allows us to distinguish fine grains around manganese carrier residues, also observed on the fracture surface. ${ }^{[20,35]}$ A fine-grain structure around manganese residues together with a more extended manganese solution (than is expected on the base of only diffusion mechanisms) point at manganese solution by a more complex mechanismdiffusion induced grain boundary motion (DIGM). This phenomenon of alloying with the presence of gas phase for an iron-manganese system first was described by Navara $^{[5]}$ and was developed further by Salak, ${ }^{[8]}$ and it emphasizes the importance of the presence of manganese vapor in admixed systems. Detailed research about manganese solution in the discussed systems is presented elsewhere. $^{[35]}$

\section{CONCLUSIONS}

A detailed analysis of three manganese-containing sintered steels with the same nominal composition Fe-0.8Mn-0.5C, prepared on the base of fully prealloyed powder and iron powder, admixed with high-purity electrolytic manganese and medium-carbon ferromanganese, indicates higher brittleness during all processing and after sintering for the admixed materials. The lower strength of the admixed materials is described based on the oxidation of such materials during the heating stage. Intensive oxidation of manganese vapor and its subsequent condensation on the surrounding iron particles suppress interparticle necks development in the areas extending up to a couple of hundred micrometers around the manganese source. The worst results in terms of mechanical properties were obtained for material admixed with electrolytic manganese; the reason being the more intensive manganese sublimation and accordingly the higher specimen oxidation at low temperatures when thermodynamic conditions are too oxidizing. A second type of critical defects was found for both admixed systems as well that was connected with the degradation of grain boundaries around the manganese carrier particles as a result of the presence of complex oxides and manganese sulfide on the intergranular decohesion facets. The composition, morphology, and location of the contaminants after sintering are dictated by the type of manganese carrier used and the sintering conditions (temperature profile, sintering atmosphere purity, etc.). High-temperature sintering at good atmosphere purity $\left(\mathrm{DP}<218 \mathrm{~K}\left[-55^{\circ} \mathrm{C}\right]\right)$ results in an almost full reduction of oxides, and the final residues are manganese sulfides located on free powder surface (pores). These features have no detrimental influence on mechanical properties. The microstructure development of prealloyed material indicates a much faster carbon dissolution in comparison with admixed materials. A fine-grain structure around ferromanganese residues together with an extended manganese dissolution point to a manganese solution by the more complex mechanism-DIGM.

Use of hydrogen-containing atmospheres, lowtemperature delubrication, higher heating rate in the medium temperatures range $\left(973 \mathrm{~K}\left[700{ }^{\circ} \mathrm{C}\right]\right.$ to $1273 \mathrm{~K}$ $\left[1000{ }^{\circ} \mathrm{C}\right]$ ), together with controlled high-purity atmospheres and sintering at high temperatures $(\geq 1473 \mathrm{~K}$ $\left.\left[1200^{\circ} \mathrm{C}\right]\right)$, are suggested for the successful sintering of PM steels admixed with manganese. A lower sensitivity to oxidizing conditions during the heating stage, characteristic for prealloyed material that results in a much lower oxygen content and in a lower carbon loss after sintering, homogeneously distributed microstructure, absence of large contaminated pores and oxide inclusions indicate the definite advantage of a prealloyed powder system from both economical and technical points of view.

\section{ACKNOWLEDGMENTS}

The main part of this work was done in the framework of the Höganäs Chair III project. The authors would like to thank Höganäs AB for financial support, scientific cooperation, and permission to publish this paper. Erachem Comilog is greatly acknowledged for the supply of electrolytic manganese and ferromanganese powder.

\section{REFERENCES}

1. I. Cremer: Proc. Euro PM 2008, EPMA, Mannheim, Germany, 2008.

2. G. Zapf, G. Hoffmann, and K. Dalal: Powder Metall., 1975, vol. 18 , pp. 214-36.

3. G. Hoffmann and K. Dalal: Powder Metall., 1979, vol. 11, pp. $177-80$

4. G. Schlieper and F. Thummler: Powder Metall., 1979, vol. 11, pp. 172-76

5. E. Navara: Proc. of VI $I^{\text {th }}$ Int. Powder Metall. Conf., vol. 1, Brno, CSSR, 1982, pp. 143-54.

6. A. Šalak: Int. J. Powder Metall. Powder Tech., 1980, vol. 16, pp. 369-79

7. A. Salak: Powder Metall., 1980, vol. 12, pp. 72-75.

8. A. Šalak: Kovove Mater., 1989, vol. 27, pp. 159-70.

9. A. Šalak: Sci. Sintering, 1989, vol. 21, pp. 145-54.

10. A. Šalak, M. Selecka, and R. Bureš: Powder Metall., 2001, vol. 1, pp. 41-58.

11. A. Šalak and M. Selecka: Powder Metall., 2008, vol. 51, pp. 327-39

12. A.N. Klein, R. Oberacker, and F. Thummler: Powder Metall., 1985, vol. 17, pp. 71-74.

13. E. Dudrova, M. Kabatova, R. Bidulsky, and A. Wronski: Powder Metall., 2004, vol. 47, pp. 181-90.

14. E. Dudrova, M. Kabatova, R. Bures, R. Bidulsky, and A.S. Wronski: Kovove Mater., 2005, vol. 43, pp. 404-21.

15. H. Danninger, R. Pöttschcher, S. Bradac, A. Salak, and J. Seykammer: Powder Metall., 2005, vol. 48, pp. 23-32.

16. A. Cias, S.C. Mitchell, A. Watts, and A.S. Wronski: Powder Metall., 1999, vol. 42, pp. 227-33.

17. A. Cias, S.C. Mitchel, K. Plich, A. Cias, M. Sulovski, and A.S. Wronski: Powder Metall., 2003, vol. 46, pp. 165-70. 
18. M. Campos, D. Sanchez, and J.M. Torralba: J. Mater. Process. Tech., 2003, vols. 143-144, pp. 464-69.

19. E. Hryha and E. Dudrova: Mater. Sci. Forum, 2007, vols. 534-536, pp. 761-64.

20. E. Hryha: Ph.D. Dissertation, IMR SAS, Kosice, Slovakia, 2007.

21. E. Hryha, L. Nyborg, E. Dudrova, and S. Bengtsson: Powder Metall., 2008, vol. 8, pp. 109-14.

22. S. Sainz, V. Martinez, M. Dougan, F. Baumgaertner, and F. Castro: Adv. Powder Metall. Part. Mater., San Diego, CA, 2006, pp. 624-37.

23. P. Beiss and R. Wassenberg: Proc. Euro PM2005, vol. 1, EPMA, Prague, Czech Republic, 2005, pp. 143-50.

24. P. Beiss: Adv. Powder Metall. Part. Mater., San Diego, CA, 2006, pp. 727-35.

25. K. Ogura, S. Takajo, N. Yamato, Y. Maeda, and Y. Morioka: Met. Powder Rep., 1987, vol. 42, pp. 292-94.

26. S. Unami and O. Furukumi: J. Jpn. Soc. Powder Metall., 1993, vol. 40, pp. 630-36.
27. M. Johansson: Met. Powder Rep., 1999, vol. 54, pp. 22-24.

28. H. Karlsson, L. Nyborg, and S. Berg: Powder Metall., 2005, vol. 48 , pp. $51-58$.

29. E. Hryha, C. Gierl, L. Nyborg, H. Danninger, and E. Dudrova: Appl. Surf. Sci., 2010, vol. 256, pp. 3946-61.

30. E. Hryha, E. Dudrova, and S. Bengtsson: Powder Metall., 2008, vol. 51 , pp. $340-42$.

31. E. Hryha, E. Dudrova, and S. Bengtsson: Proc. Euro PM2007, vol. 3, EPMA, Toulouse, France, 2007, pp. 3-8.

32. E. Hryha, P. Zubko, E. Dudrová, L. Pešek, and S. Bengtsson: J. Mater. Process. Tech., 2009, vol. 209, pp. 2377-85.

33. D.R. Gaskell: Introduction to the Thermodynamics of Materials, 4th ed., Taylor \& Francis, New York, NY, 2003, p. 618.

34. E. Hryha, L. Nyborg, E. Dudrova, and S. Bengtsson: Proc. Euro PM2009, vol. 1EPMA, Copenhagen, Denmark, 2009, pp. 17-22.

35. E. Hryha, E. Dudrova, and L. Nyborg: Unpublished research, Chalmers University of Technology, Gothenburg, Sweden, 2010. 